Article

\title{
Retrieval and Multi-scale Validation of Soil Moisture from Multi-temporal SAR Data in a Semi-Arid Tropical Region
}

\author{
Sat Kumar Tomer ${ }^{1}$, Ahmad Al Bitar ${ }^{1}$, Muddu Sekhar ${ }^{2, *}$, Mehrez Zribi ${ }^{1}$, S. Bandyopadhyay ${ }^{3}$, \\ K. Sreelash ${ }^{2}$, A.K. Sharma ${ }^{2}$, Samuel Corgne ${ }^{4}$ and Yann Kerr ${ }^{1}$ \\ ${ }^{1}$ Centre d'Etudes Spatiales de la Biosphere (CESBIO), 31400 Toulouse, France; \\ E-Mails: satkumartomer@gmail.com (S.K.T.); ahmad.albitar@cesbio.cnes.fr (A.A.B.); \\ mehrez.zribi@cesbio.cnes.fr (M.Z.); yann.kerr@cesbio.cnes.fr (Y.K.) \\ ${ }^{2}$ Department of Civil Engineering, Indian Institute of Science, Bangalore 560012, India; \\ E-Mails: ragasree02@gmail.com (K.S.); amitsharma.isro@gmail.com (A.K.S.) \\ ${ }^{3}$ Indian Space Research Organization, Bangalore 560097, India; E-Mail: bandyo@isro.gov.in (S.B.) \\ ${ }^{4}$ LETG Rennes Costel, UMR 6554 CNRS, 350043 Rennes, France; E-Mail: samuel.corgne@uhb.fr \\ * Author to whom correspondence should be addressed; E-Mail: muddu@ civil.iisc.ernet.in; \\ Tel.: +91-80-2293-2245.
}

Academic Editors: Nicolas Baghdadi and Prasad S. Thenkabail

Received: 25 February 2015 / Accepted: 11 June 2015 / Published: 18 June 2015

\begin{abstract}
The current study presents an algorithm to retrieve surface Soil Moisture (SM) from multi-temporal Synthetic Aperture Radar (SAR) data. The developed algorithm is based on the Cumulative Density Function (CDF) transformation of multi-temporal RADARSAT-2 backscatter coefficient (BC) to obtain relative SM values, and then converts relative SM values into absolute SM values using soil information. The algorithm is tested in a semi-arid tropical region in South India using 30 satellite images of RADARSAT-2, SMOS L2 SM products, and 1262 SM field measurements in 50 plots spanning over 4 years. The validation with the field data showed the ability of the developed algorithm to retrieve SM with RMSE ranging from 0.02 to $0.06 \mathrm{~m}^{3} / \mathrm{m}^{3}$ for the majority of plots. Comparison with the SMOS SM showed a good temporal behaviour with RMSE of approximately $0.05 \mathrm{~m}^{3} / \mathrm{m}^{3}$ and a correlation coefficient of approximately 0.9. The developed model is compared and found to be better than the change detection and delta index model. The approach does not require calibration of any parameter to obtain relative SM and hence can easily be extended to any region having time series of SAR data available.
\end{abstract}


Keywords: soil moisture; SAR; multi-temporal; CDF; RADARSAT-2; SMOS

\section{Introduction}

Knowledge of Soil Moisture (SM) is useful for climatology, meteorology, hydrology and agriculture [1]. Wood et al. [2] pointed out the requirement of higher resolution (1 $\mathrm{km}^{2}$ or finer) observations of land surface variables as one of six grand challenges ahead for hydrology. Estimation of SM over large region and time periods through in situ observations is cumbersome, while satellite remote sensing through optical or microwave sensors can estimate SM with a broad spatial coverage and repeat temporal coverage [3]. The optical sensors are hampered by cloud cover, while the microwave sensors have all weather penetration capability. Passive microwave sensors (e.g., SMOS) provide SM globally at a relatively coarser spatial resolution and can not meet the requirement of higher resolution SM. Active microwave sensors (e.g., RADARSAT-2) can meet the requirement of higher resolution SM though with a relatively coarse temporal resolution (2-4 weeks) [4].

Retrieval of SM from active microwave is difficult as apart from SM, measured BC is also influenced by surface roughness and vegetation canopy structure [5]. Several physically based, empirical and semi-empirical models have been developed to retrieve SM. Physically based models have been applied to retrieve the SM successfully [6,7], but these models require extensive information regarding the vegetation and soil surface, which might be difficult to obtain at a larger scale. Several empirical, regression or machine learning based models have been used to retrieve the SM with relative success (e.g., [8-12]). A major disadvantage of these models is the requirement of extensive in situ SM to calibrate the models. The resulting models are also site specific and can not be used for other climate, soil and vegetation conditions. An overview of the commonly used approaches for retrieving SM along with their physical principles, advantages and limitations can be found in [13].

For the regional estimation of SM, models based on change detection (CD) have been developed to retrieve SM by utilizing the temporal data [14-16]. These models utilize the difference between a dry and wetter image BC to minimize the impact of soil and vegetation on BC. SM is retrieved by assuming a linear relationship between the difference in BC and the SM [10]. The coefficients of the linear relationship are obtained by regression and require site specific calibration. By using a long term temporal data, [14] developed a model whose coefficients are related to the minimum and maximum observed SM, which are computed from the soil information and hence avoided the requirement of a site specific calibration. The delta index (DI) approach proposed by [16] normalizes the difference in BC by the $\mathrm{BC}$ in dry condition to obtain directly the SM without requiring any calibration and soil information. All these models assume a linear relationship between SM and the change in BC, which might not hold true in some cases (e.g., $[6,11,17,18])$.

In the current study, an empirical CDF Transformation (CT) is proposed to normalize the BC. CDF transformation is used here as an optimal multi-linear estimate between backscatter coefficient and surface soil moisture enabling the spatialization of the model over the area of interest with an intrinsic parameter estimation. The use of CDF approach not as a stochastic model but as an explicit model 
has been used in previous studies like [19] for normalization of incidence angle. The relationship between BC and SM may be nonlinear but it is a monotonic relationship. CT can convert a monotonic nonlinear relationship into linear and avoids the need of the assumption of linearity used in the CD based approaches. Another advantage of using empirical CT is that it does not rely only on one point (dry image) or two points (dry and wet image) to normalize the $\mathrm{BC}$, rather it utilizes the entire time series for normalization. This minimizes the error introduced by the possible uncertainty in the dry or wet image. Similar to the CD approach, empirical CT also provides the relative SM, which needs to be converted into absolute SM by using the soil information and does not require site specific calibration.

The main objectives of the current study are to: (i) asses the accuracy of CT model retrieved SM at higher resolution from $\mathrm{BC}$ time series, (ii) comparison of the performance of CT model with existing similar approaches (CD and DI model) in retrieving SM at higher resolution, (iii) evaluate the impact of number of images available on the SM retrieval accuracy, and (iv) study the impact of uncertainty in the $\mathrm{BC}$ (arising by ignoring the temporal variation of soil roughness and vegetation) on the retrieved SM at higher resolution. The models are applied in retrieving SM using 30 images of RADARSAT-2 spanning over four years in an experimental watershed in South India. A multi-scale validation is performed: at local scale by comparing the retrieved SM with the field data (SM measured in 50 plots) and at coarse scale by upscaling and comparing with the available SM products from SMOS.

\section{Study Area and Data Set}

The study is applied over Berambadi watershed located near to Gundlupet town in Chamarajanagar district of Karnataka state in South India (Figure 1). It is part of the ongoing project "Assimilation of Multi-satellite at Berambadi watershed for Hydrology And land Surface experiments (AMBHAS)" (www.ambhas.com). The main objectives of AMBHAS is to validate remote sensing products and to integrate them into a land data assimilation system. For the present study, an area of $625 \mathrm{~km}^{2}$ $(25 \mathrm{~km} \times 25 \mathrm{~km})$ is selected around the Berambadi watershed. The study area lies in semi-arid climate zone with a mean annual dominant South-West monsoon rainfall of $800 \mathrm{~mm}$. Based on the latest Köppen-Geiger updated world climate classification [20], the study area is classified as AWh (Equatorial, Desert/arid, Dry). It has Bandipur National park at its west boundary. The main three soil types in the area are comprising of black, red and rocky/weathered soils, as identified by the geophysical studies. These are representative of the soil types for granitic/gnessic lithology found in South India [21]. The main land use classes encountered in the area are: dense/closed forest, scrub forest, land with scrub, Kharif (summer) crop, double crop and plantation. During Kharif (summer) and Rabi (winter) marigold, sunflower, finger millet, maize, garlic, sugarcane, sorghum, water-melon, lentils, and groundnut etc., are grown [22,23]. 


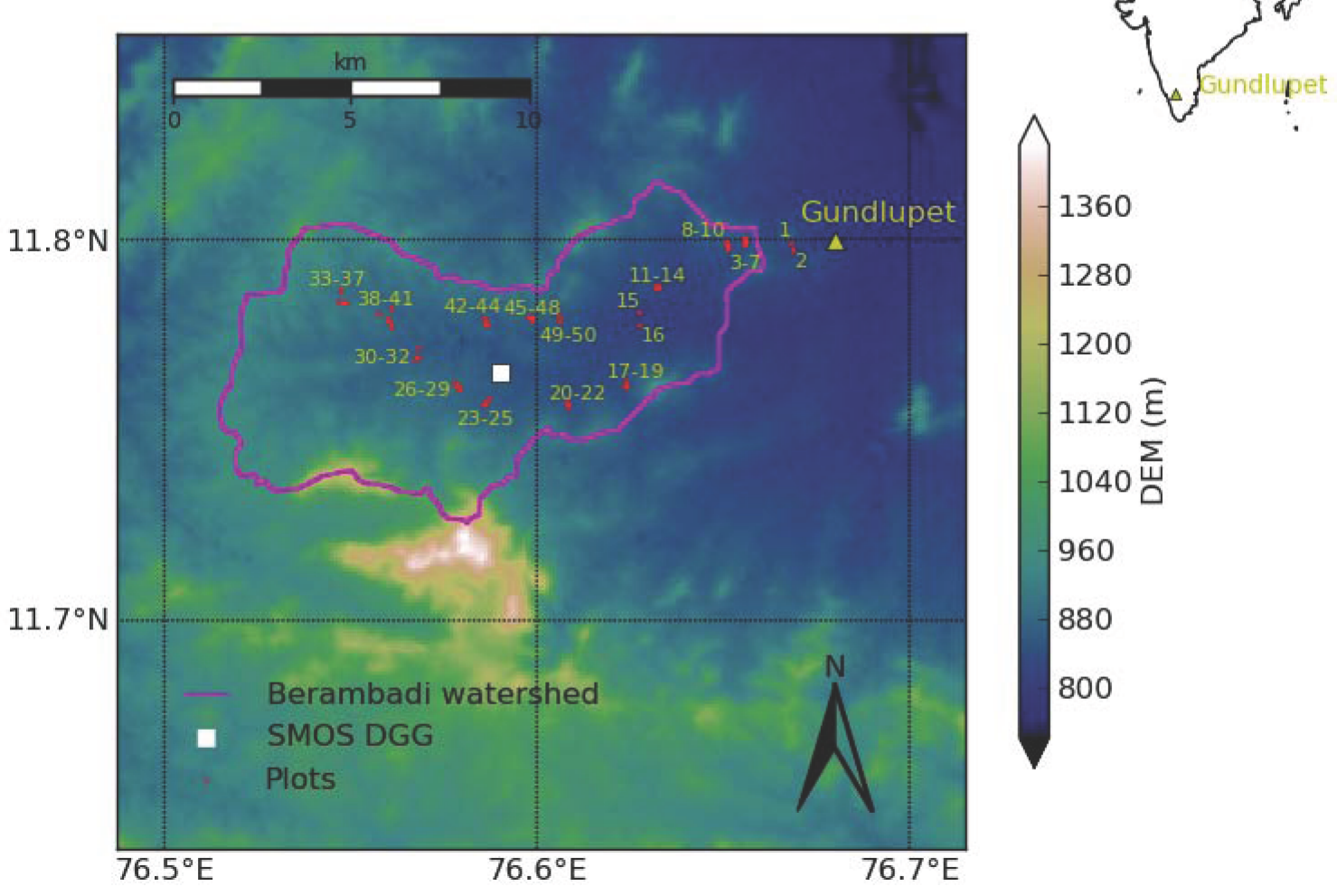

Figure 1. Location of the study area inside India (shown in inset) and Digital Elevation Model (DEM) of the study area along with the location of field plots and SMOS DGG.

Digital Elevation Model (DEM) obtained by processing the Cartosat-1 data at a spatial resolution of $30 \mathrm{~m}$ is available for entire India [24]. The DEM for the study area is shown in Figure 1. The elevation shows a significant variation with the difference in minimum and maximum elevation being approximately $600 \mathrm{~m}$. The soil map prepared by Karnataka State Remote Sensing Application Centre (KSRSAC), Bangalore, India based on panchromatic and Linear Imaging Self Scanner (LISS) III merged, Indian Remote Sensing (IRS) satellite images at the scale of 1:50000 is used in this study [25]. The soil map of the study area is shown in Figure 2a. The soil in the watershed comprises of Sandy Clay, Clay, Sandy Clay Loam, Clay Loam, Sandy Loam and Loamy Sand. The land cover map available at a spatial resolution of $1 \mathrm{~km}$ from ECOCLIMAP which is used in the SMOS retrieval processor [26] divides the land cover in the study area into two classes, (i) nominal surface (low vegetation and bare soil) and (ii) forest (dense vegetation). The spatial distribution of nominal and forest surface is shown in Figure $2 b$. The left side of the study area, which is covered by Bandipur National park, is shown as forest surface, and the right side of the study area, which is mainly covered by crops or is barren, is shown as nominal surface. Using the Rosetta pedo-transfer function and fraction of clay, silt and sand, van Genuchten (VG) soil hydraulic parameters are computed for the study area [27]. These are used to compute the wilting point and field capacity. Map of the field capacity and wilting point is shown in Figure $2 \mathrm{c}-\mathrm{d}$. The wilting point varied from 0.10 to $0.16 \mathrm{~m}^{3} / \mathrm{m}^{3}$, and the field capacity varied from 0.20 to $0.32 \mathrm{~m}^{3} / \mathrm{m}^{3}$. 


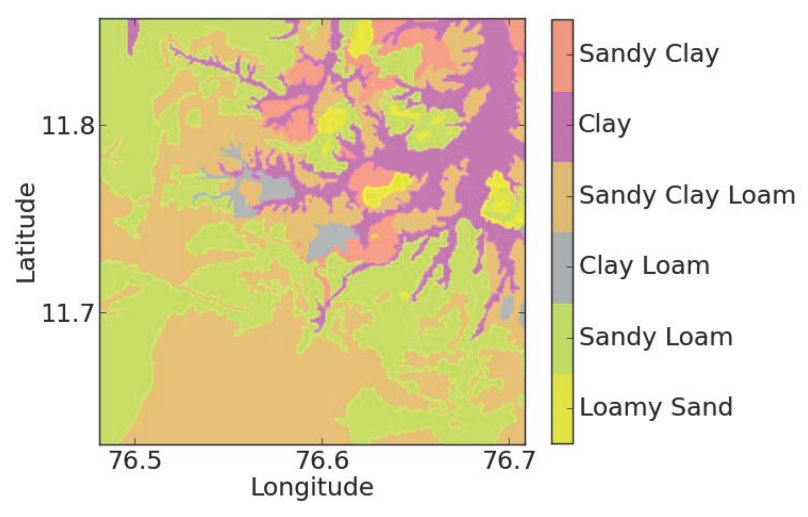

(a) Soil classes

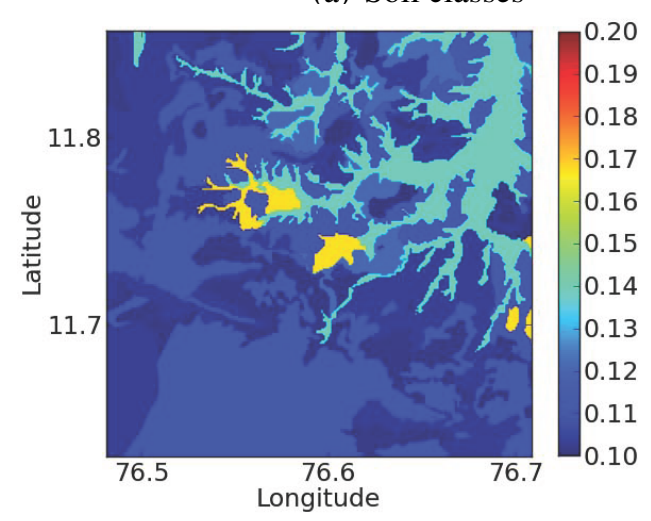

(c) Wilting point

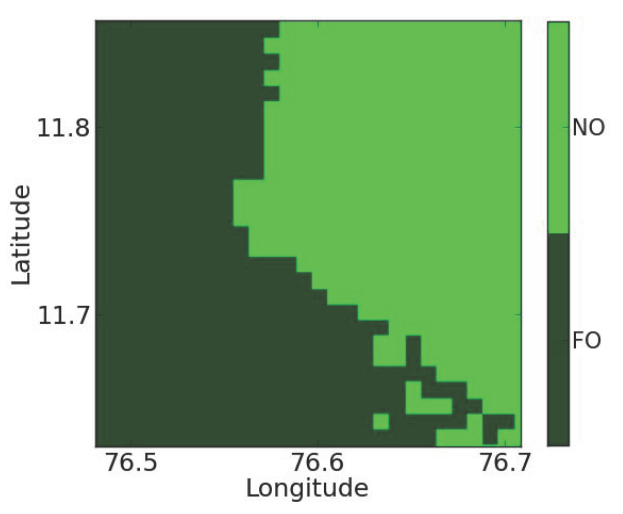

(b) Land-cover

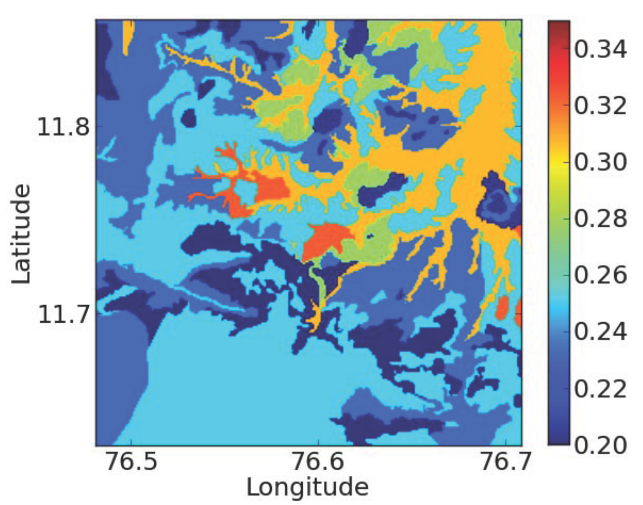

(d) Field capacity

Figure 2. Soil and land-cover map for the study area. In the land-cover, NO is the nominal surface (bare soil and low vegetation) and FO is the forest. (a) Soil classes, (b) Land-cover, (c) Wilting point, (d) Field capacity.

\subsection{Field Data Set}

The SM is measured using the SM-300 theta probes (Delta-T devices; Delta-T Devices Ltd, Cambridge, UK), which measures SM averaged over 0 to $5 \mathrm{~cm}$ depth. Local calibration of the Delta-T device using 76 gravimetric measurements showed good performance with a correlation coefficient of 0.91 and RMSE of $0.031 \mathrm{~m}^{3} / \mathrm{m}^{3}$. SM is measured manually within a window of 3 hours of the satellite pass at three locations in each field plot, and these measurements are averaged to get the plot averaged $\mathrm{SM}$. The SM is measured in 50 field plots in the watershed, and location of the monitoring field plots inside the watershed is shown in the Figure 1. The fields are chosen to be representative of the spatial heterogeneity of soil and crop types while maintaining a reasonable accessibility. The size of field plots varied approximately from $0.07 h a$ to $1.8 h a$ with an average value of $0.38 h a$. Throughout the article, $\mathrm{SM}$ is presented in volumetric unit $\left(\mathrm{m}^{3} / \mathrm{m}^{3}\right)$.

\subsection{Satellite Data Set}

RADARSAT-2 is a C-band radar having a frequency of $5.40 \mathrm{GHz}$ (wavelength equal to $5.6 \mathrm{~cm}$ ). A total of 30 RADARSAT-2 images were acquired during the period from December 2009 to August 
2013. Details (acquisition date, pixel/line spacing, pass direction, incidence angle) of the RADARSAT-2 images used in the study are given in Table 1 . The local overpass time of ascending and descending direction is 6:30 PM and 6:30 AM respectively. All the images are fine quad polarization geocoded products. Incidence angle of the images varied between 21 to 25 degree. Lambert's law of optics is used to correct the $\mathrm{BC}$ for the incidence angle variation [28], which has been successfully used in previous studies (e.g., [29]). All the images are corrected to a reference incidence angle of 23 degree. Since, the incidence angle is already close to 23 degree, a minor correction having absolute maximum of $0.15 \mathrm{~dB}$ is observed. Median filter performs better for denoising salt and pepper noise and Wiener filter works better for Gaussian and speckle noise [30]. Consequently, RADARSAT-2 data are filtered using the median and the Wiener filters with a $7 \times 7$ window size. The correction for topography is performed using the NEST toolbox [31]. Radar shadow occurs when the local incidence angle is higher than 90 degree and layover occurs when the incidence angle is higher than local slope [32]. No area is found to be affected by radar shadow. Approximately $0.4 \%$ and $1.2 \%$ area is found to be affected by layover for an incidence angle of 25 and 20 degree respectively, and is masked out. Plot scale BC is obtained by taking the median of the data sampled at $5 \mathrm{~m}$ grid. Throughout the article $\mathrm{BC}$ is presented in $\mathrm{dB}$. For the computation of SM for entire study area, RADARSAT-2 images are aggregated to a grid size of $20 \mathrm{~m}$.

SMOS-L2 version 551 SM products from ascending and descending overpasses are used in the study. SMOS is a L-band radiometer operating at a frequency of $1.4 \mathrm{GHz}$ (wavelength equal to $21 \mathrm{~cm}$ ) [26]. The SM at a temporal resolution of 3 days and at a spatial resolution of approximately $40 \mathrm{~km}$ from SMOS is available from January 2010. The Discrete Global Grid (DGG) of the SMOS data products is Icosahedral Snyder Equal Area (ISEA) $15 \mathrm{~km}$ grid. The ID number of the DGG lying inside the study area is 3160498 , which has the latitude of $11.765 \mathrm{~N}$ and longitude of $76.590 \mathrm{E}$. The SM data are filtered for Radio Frequency Interferences (RFI) by excluding data with RFI probability higher than $10 \%$. Retrievals with higher uncertainty are also excluded using a threshold of 0.05 for the data quality index (DQX).

Table 1. Details of the RADARSAT-2 images used in the analysis.

\begin{tabular}{|c|c|c|c|c|c|c|}
\hline Year & Date/Month & $\begin{array}{l}\text { Pixel } \\
\text { Spacing } \\
\text { (m) }\end{array}$ & $\begin{array}{l}\text { Line Spacing } \\
\text { (m) }\end{array}$ & Beam Mode & Pass Direction & $\begin{array}{l}\text { Incidence } \\
\text { Angle } \\
\text { (degree) }\end{array}$ \\
\hline 2009 & $22 / 12$ & 4.73 & 5.33 & FQ3 & Ascending & 20 \\
\hline 2010 & $\begin{array}{l}15 / 01,08 / 02,04 / 03,21 / 04 \\
15 / 05,12 / 09,06 / 10,30 / 10\end{array}$ & 4.73 & 5.33 & FQ3 & Ascending & 20 \\
\hline 2011 & $\begin{array}{l}26 / 05,19 / 06,13 / 07,06 / 08 \\
30 / 08,23 / 09,14 / 10,10 / 11\end{array}$ & 4.73 & 4.70 & FQ6 & Descending & 23 \\
\hline 2012 & $\begin{array}{l}07 / 07,31 / 07,24 / 08,17 / 09 \\
11 / 10,04 / 11,28 / 11\end{array}$ & 4.73 & 4.70 & FQ6 & Descending & 24 \\
\hline 2013 & $\begin{array}{l}08 / 06,02 / 07,26 / 07,19 / 08 \\
12 / 09,06 / 10\end{array}$ & 4.73 & 4.70 & FQ6 & Descending & 25 \\
\hline
\end{tabular}




\section{Methodology}

\subsection{SM Retrieval Models}

$\mathrm{BC}$ is a function of the SM, soil roughness and vegetation. Past studies have shown the existence of nonlinear relationship between SM and BC over bare soils [6,17] and over vegetated areas [11]. A generalized nonlinear equation relating the BC to SM, as proposed by [18], can be written as,

$$
B C_{i, t}=P 1_{i, t} \times S M_{i, t}^{P 2_{i, t}}+P 3_{i, t},
$$

where, $B C$ is the backscatter coefficient $(\mathrm{dB})$ and $S M$ is the soil moisture $\left(\mathrm{m}^{3} / \mathrm{m}^{3}\right)$. Subscript $i$ is the index for the position in space and $t$ is the index for the time. The parameters $(P 1, P 2, P 3)$ are a function of soil roughness and vegetation [33]. In this formulation, the parameters are a function of space and time, and rendering their calibration is difficult. In the present study, an alternative formulation is adopted to avoid the estimation of time and space variant parameters. For sparse vegetation and when the incidence angle is low, the effect of vegetation can be ignored [34,35]. For the agricultural fields, the soil roughness is considered constant during the cropping period, and its effect is minimized by using the temporal data over the same field. Impact of these two assumptions on the SM retrieval accuracy is discusses in the Section 4.3. Under such conditions, Equation (1) can be re-formulated as,

$$
B C_{i, t}=P 1_{i} \times S M_{i, t}^{P 2_{i}}+P 3_{i} .
$$

In this formulation, the parameters are only dependant on location $(i)$. It should be noted that the parameters of Equation (2) does not vary with time, while that of Equation (1) are time variant.

Equaton (2) is a monotonically increasing function, which can be transformed into a linear function by CDF transformation (CT) [36]. This is presented schematically in Figure 3. Since the parameters of Equation (2) are constant in time and vary only in space, the computation of CDF should be done using the temporal data over same spatial location.
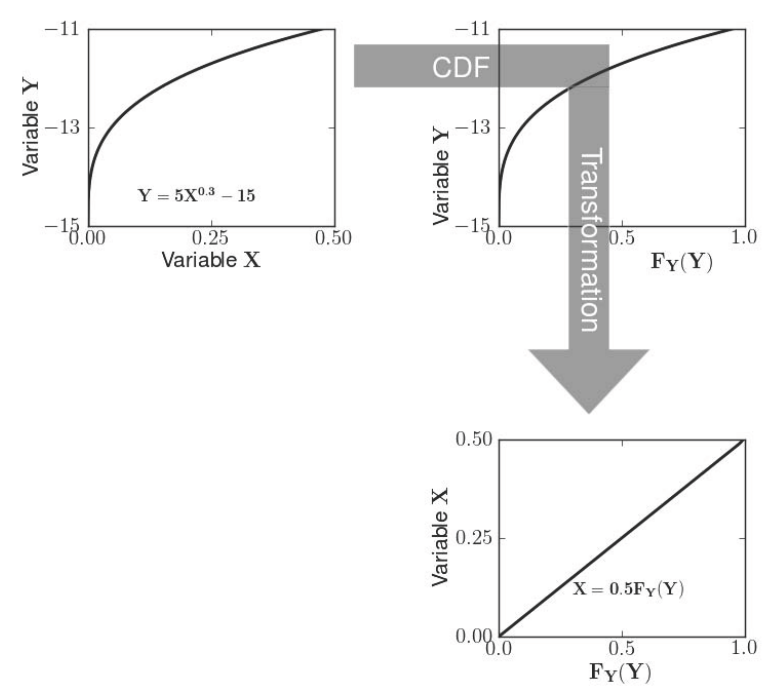

Figure 3. Transformation of monotonically increasing nonlinear function to linear function using the CDF transformation. Here $X$ represents the SM, $Y$ corresponds to backscatter coefficient, and $F_{Y}(Y)$ is the CDF transformed backscatter coefficient. 
By doing the CDF transformation of Equation (2), the nonlinearity can be avoided. The CDF transformation of $\mathrm{BC}$ results in a variable, ranging between 0 to 1 (see Figure 3), which corresponds to the minimum and maximum relative SM respectively. Hence, this transformed BC can be assumed as the relative SM,

$$
R S M_{i, t}=F_{B C, i}\left(B C_{i, t}\right)
$$

where, $R S M$ is the relative SM.

Relative SM can be converted into absolute SM using the minimum and maximum soil moisture data [14]:

$$
S M_{i, t}=S M_{\min , i}+\left(S M_{\max , i}-S M_{\min , i}\right) \times R S M_{i, t},
$$

where, $S M_{\min , i}$ and $S M_{\max , i}$ are the minimum and maximum observed soil moisture for a location $i$. After replacing the $R S M_{i, t}$ from Equation (3), the resulting equation to retrieve the SM from $B C$ can be written as,

$$
S M_{i, t}=S M_{\min , i}+\left(S M_{\max , i}-S M_{\min , i}\right) \times F_{B C, i}\left(B C_{i, t}\right) .
$$

In an arid/semi-arid climate, the minimum surface SM could be 0.5 of the wilting point $\left(\theta_{w p}\right)$ [37]. In the humid climate, the minimum SM could be higher than the $\theta_{w p}$ and can go up to the $\theta_{s}$ (saturated $\mathrm{SM}$ ). In the case of arid/semi-arid climate, the maximum surface SM could be approximated to the field capacity $\left(\theta_{f c}\right)$, given the fact that the satellite pass occurs approximately every four weeks, and it would be very unlikely that SM would be above the field capacity except few local fields. Hence, in semi-arid regions with high temporal dynamic of soil moisture due to high evaporation level and high intensity of rainfall event, the $S M$ can be computed as,

$$
S M_{i, t}=0.5 \theta_{w p, i}+\left(\theta_{f c, i}-0.5 \theta_{w p, i}\right) \times F_{B C, i}\left(B C_{i, t}\right),
$$

where $B C$ is the backscatter coefficient $(\mathrm{dB})$. The $C D F$ of $B C$ is computed using the temporal data over the same spatial location. Given a time series of $B C$ data having same incidence angle along with the soil $\left(\theta_{w p}\right.$ and $\left.\theta_{f c}\right)$ data, SM can be estimated using the Equation (6), which avoids the estimation of pixel specific parameters $\left(P 1_{i}, P 2_{i}\right.$, and $\left.P 3_{i}\right)$. Nonparametric kernel density estimator is used to compute the CDF of $B C$ [38].

The suggested approach is compared with DI and CD approaches. The delta index model to retrieve the SM by [16] is expressed as,

$$
S M_{i, t}=\left|\frac{B C_{i, t}-B C_{i, d r y}}{B C_{i, d r y}}\right|,
$$

where, $B C_{i, d r y}$ is the backscatter coefficient at a dry soil condition.

SM can be retrieved using the change detection method [14] as,

$$
R S M_{i, t}=\frac{B C_{i, t}-B C_{i, d r y}}{B C_{i, w e t}-B C_{i, d r y}},
$$

where, $B C_{i, w e t}$ is the backscatter coefficient representing the wet soil condition. The highest and lowest observed value of $B C_{i}$ time series are used for $B C_{i, w e t}$ and $B C_{i, d r y}$ respectively [14]. Similar to the CT approach, Equation (4) is used to convert the $R S M$ into $S M$. 


\subsection{Multi-Scale Validation of RADARSAT-2 Retrieved SM}

A multi-scale validation of the retrieved SM is performed using the field measured and SMOS SM. Since, the spatial resolution of the SM retrieved from RADARSAT- 2 is finer $(20 \mathrm{~m})$ than the spatial resolution of the soil moisture from SMOS $(40 \mathrm{~km})$, considering that, the soil moisture from the RADARSAT- 2 is up-scaled to the coarser scale. Since, RADARSAT-2 and SMOS have different bands and hence different penetration depths, they need to be compared and corrected for bias [39].

There are mainly three kind of heterogeneity (soil type, land cover and antenna footprint) within a SMOS node that impacts the up-scaling of soil moisture [40]. The up-scaled soil moisture $\left(\overline{S M_{t}}\right)$ can be computed as,

$$
\overline{S M_{t}}=\sum S H_{i} \times S M_{i, t}
$$

where, $S H$ is the combined effect of different spatial heterogeneities and is computed as,

$$
S H_{i}=\frac{L C_{i} \times C F_{i} \times M A F_{i}}{\sum L C_{i} \times C F_{i} \times M A F_{i}},
$$

where, $L C$ is the land cover value ( 0 for forest surface; 1 for nominal surface), $C F$ is the clay fraction which is used to account for soil texture variability, $M A F$ is the mean antenna footprint. The mean antenna footprint for SMOS has a value of 1 in the center of SMOS grid, and it decreases as the distance from the center of pixel increases, and has a value of around 0.5 at a distance of $20 \mathrm{~km}$ [40].

Table 2. Range (minimum-maximum) of spatial heterogeneity for up-scaling the RADARSAT-2 soil moisture using eight strategies. A value of 1 represents that spatial heterogeneity is neglected by assuming a constant value for all the pixels.

\begin{tabular}{cccc}
\hline S.N. & Mean Antenna Footprint & Land Cover & Soil Texture \\
\hline 1 & 1 & 1 & 1 \\
2 & $0.48-1.0$ & 1 & 1 \\
3 & 1 & $0-1$ & 1 \\
4 & $0.48-1.0$ & $0-1$ & 1 \\
5 & 1 & 1 & $0.08-0.56$ \\
6 & $0.48-1.0$ & 1 & $0.08-0.56$ \\
7 & 1 & $0-1$ & $0.08-0.56$ \\
8 & $0.48-1.0$ & $0-1$ & $0.08-0.56$ \\
\hline
\end{tabular}

Eight strategies are used to up-scale the RADARSAT-2 soil moisture. They are presented in Table 2. For example, strategy 1 does not consider any source of heterogeneity and assumes a value of 1 for all the pixels for all source of heterogeneity, and strategy 6 consider the mean antenna footprint and soil texture while neglecting the land cover heterogeneity by assuming a value of 1 for all the pixels. All the eight sets of up-scaled RADARSAT-2 soil moisture product are compared with the SMOS soil moisture while separating ascending and descending passes. The best up-scaling strategy corresponding to lowest RMSE and highest correlation is identified. 


\section{Results and Discussion}

All the four polarizations are used to retrieve the soil moisture using all the three models. First, results for $\mathrm{HH}$ polarization from the three (CT, CD and DI) model are described. Then, the results from CT models are discussed in detail for spatial and temporal behavior. Followed by the discussion of retrieval error from all the three models and for all the four polarizations, along with the sensitivity analysis (effect of number of available data and uncertainty in the BC).

\subsection{Results for $\sigma_{H H}$}

The retrieved soil moisture from the three models are compared with field measured soil moisture for the 50 plots through Taylor diagram, presented in Figure 4. The standard deviations are represented through their ratio over the standard deviations of the observations, and hence should ideally be equal to 1 . The observed correlation coefficient from all the three model is similar and range between 0.4 to 0.8 for most of the plots. CT and CD models showed the normalized standard deviation relatively closer to the ideal value of 1 , while DI model showed relatively higher value for most of the plots. CT and CD models outperformed the DI model for almost all the plots. No significant difference is observed between the performance of CT and CD models.

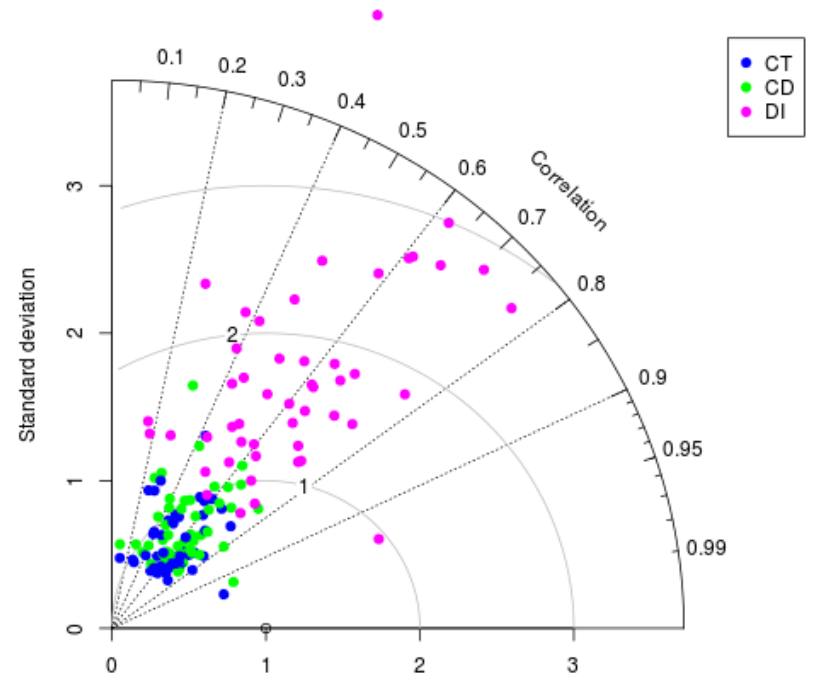

Figure 4. Taylor diagram comparing the retrieved soil moisture from CT, CD and DI model with the field measured soil moisture in 50 plots.

The comparison of the SM retrieved from the CT model using RADARSAT- $2 \sigma_{H H}$ (HH polarization $\mathrm{BC}$ ) with the SM measured in 50 plots is shown in Figure 5. The error indices (correlation, bias, and RMSE) comparing the retrieved soil moisture with the measured soil moisture along with the number of data points for each plot are presented in Table 3. Histogram of these indices is presented in Figure 6. The retrieved soil moisture showed a good comparison with the field measured soil moisture. The bias showed approximately uniform distribution with a mean and median approximately equal to 0. Approximately half of the plots showed absolute bias lesser than 0.03. The nil average bias 
observed from 50 plots, can be assumed to hold good for the up-scaled soil moisture. Most of the plots (approximately 70\%) showed RMSE lesser than 0.09, with the median equal to 0.07. Correlation for more than $80 \%$ of the plots is higher than 0.4 , with a median of 0.61 . Similar range of correlation is observed in [41] over National Airborne Field Experiment (NAFE) 2005 by retrieving the SM using the change detection approach with the ENVISAT Advanced Synthetic Aperture Radar (ASAR) Global Monitoring (GM) data which has the spatial resolution of $1 \mathrm{~km}$. Though a slightly higher RMSE was observed in [41] with RMSE of 0.14 and $0.15 \mathrm{~m}^{3} / \mathrm{m}^{3}$ for croplands and pastures respectively. Study by [42] using the change detection and ENVISAT ASAR GM data over Oklahoma also reported the same range of correlation.

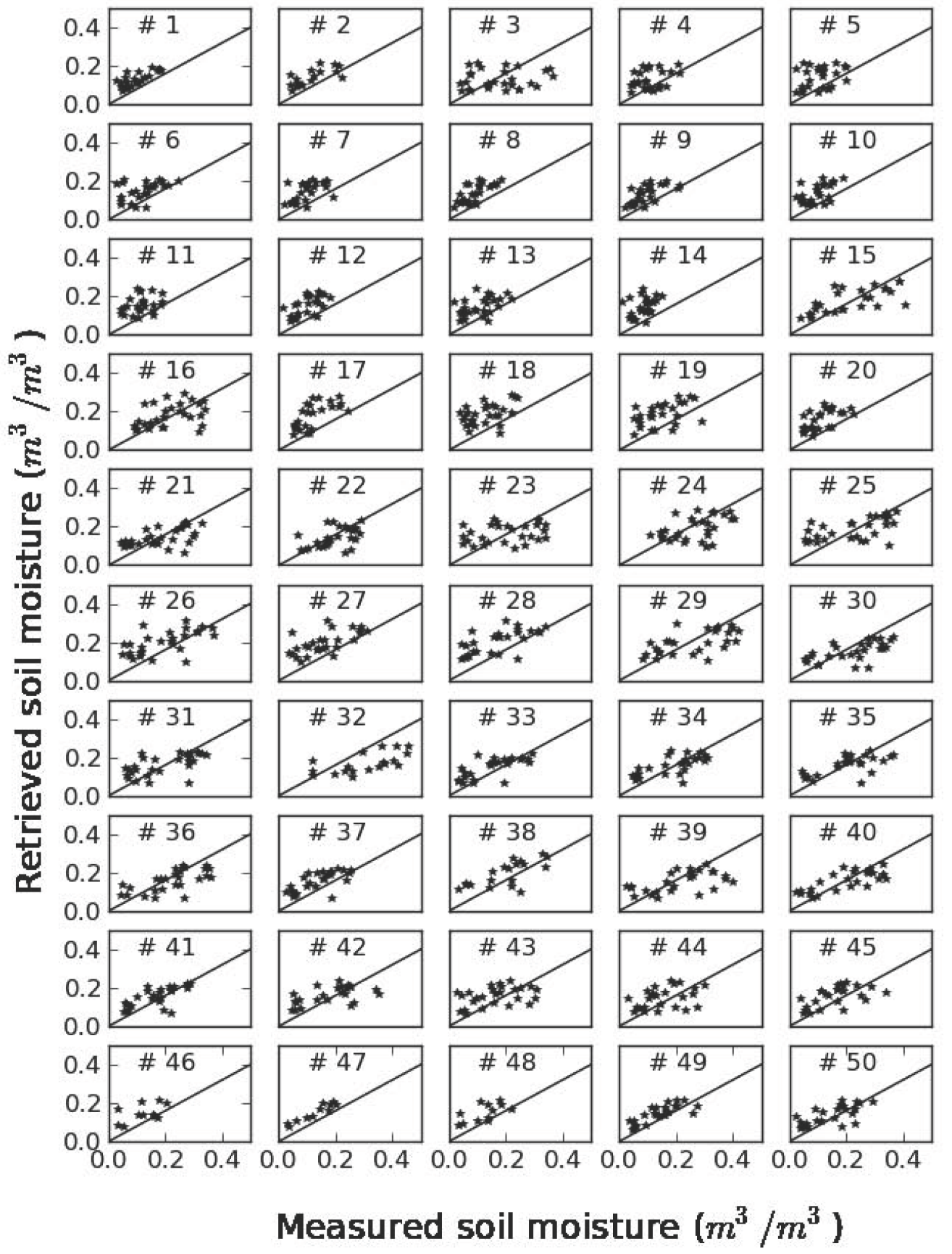

Figure 5. Scatter plot of the soil moisture retrieved using the CT model from the RADARSAT- 2 against the field measured data in 50 plots. 
Table 3. Model performance indices of the CT model using the RADARSAT- $2 \mathrm{HH}$ polarization for the 50 plots. Unit for RMSE and Bias is $m^{3} / m^{3}$.

\begin{tabular}{cccccccccc}
\hline Plot \# & $\mathbf{n}$ & $\mathbf{R}$ & $\mathbf{R M S E}$ & Bias & Plot \# & $\mathbf{n}$ & $\mathbf{R}$ & $\mathbf{R M S E}$ & Bias \\
\hline 1 & 23 & 0.77 & 0.05 & -0.03 & 26 & 28 & 0.61 & 0.08 & -0.01 \\
2 & 17 & 0.72 & 0.05 & -0.03 & 27 & 27 & 0.64 & 0.07 & -0.04 \\
3 & 28 & 0.11 & 0.11 & 0.04 & 28 & 28 & 0.66 & 0.08 & -0.04 \\
4 & 28 & 0.28 & 0.06 & -0.02 & 29 & 27 & 0.61 & 0.11 & 0.06 \\
5 & 26 & 0.25 & 0.07 & -0.04 & 30 & 28 & 0.62 & 0.10 & 0.06 \\
6 & 27 & 0.45 & 0.06 & -0.03 & 31 & 28 & 0.60 & 0.08 & 0.03 \\
7 & 27 & 0.57 & 0.07 & -0.05 & 32 & 19 & 0.63 & 0.16 & 0.13 \\
8 & 28 & 0.74 & 0.06 & -0.05 & 33 & 26 & 0.71 & 0.06 & 0.00 \\
9 & 28 & 0.67 & 0.05 & -0.04 & 34 & 26 & 0.67 & 0.07 & 0.03 \\
10 & 27 & 0.54 & 0.06 & -0.04 & 35 & 24 & 0.65 & 0.09 & 0.04 \\
11 & 25 & 0.30 & 0.07 & -0.04 & 36 & 26 & 0.67 & 0.09 & 0.06 \\
12 & 26 & 0.60 & 0.07 & -0.05 & 37 & 26 & 0.71 & 0.05 & -0.02 \\
13 & 28 & 0.50 & 0.07 & -0.04 & 38 & 19 & 0.70 & 0.07 & 0.00 \\
14 & 27 & 0.42 & 0.08 & -0.06 & 39 & 26 & 0.54 & 0.11 & 0.06 \\
15 & 26 & 0.68 & 0.09 & 0.03 & 40 & 26 & 0.74 & 0.08 & 0.04 \\
16 & 28 & 0.39 & 0.09 & 0.03 & 41 & 26 & 0.67 & 0.05 & 0.01 \\
17 & 25 & 0.66 & 0.08 & -0.06 & 42 & 24 & 0.55 & 0.08 & 0.02 \\
18 & 28 & 0.47 & 0.08 & -0.06 & 43 & 26 & 0.40 & 0.08 & 0.00 \\
19 & 28 & 0.30 & 0.11 & -0.02 & 44 & 25 & 0.39 & 0.07 & 0.01 \\
20 & 27 & 0.61 & 0.07 & -0.05 & 45 & 25 & 0.55 & 0.07 & 0.00 \\
21 & 28 & 0.52 & 0.08 & 0.04 & 46 & 12 & 0.48 & 0.06 & -0.02 \\
22 & 28 & 0.49 & 0.08 & 0.05 & 47 & 11 & 0.95 & 0.03 & -0.03 \\
23 & 28 & 0.28 & 0.10 & 0.03 & 48 & 12 & 0.61 & 0.05 & -0.03 \\
24 & 28 & 0.45 & 0.11 & 0.07 & 49 & 25 & 0.80 & 0.04 & -0.01 \\
25 & 28 & 0.55 & 0.10 & 0.03 & 50 & 25 & 0.69 & 0.06 & 0.00 \\
\hline & & & & & & & & &
\end{tabular}

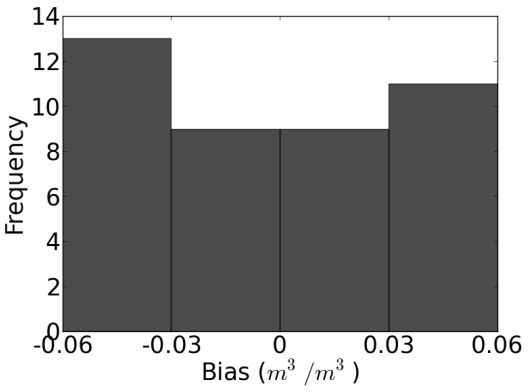

(a)

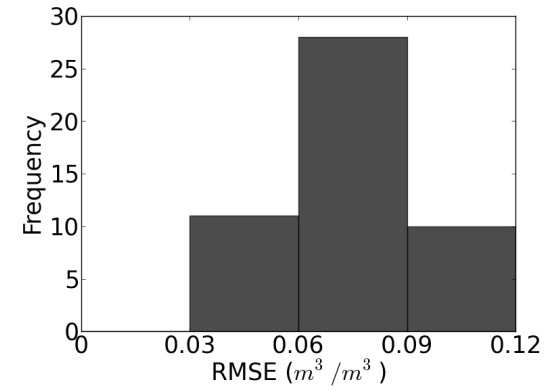

(b)

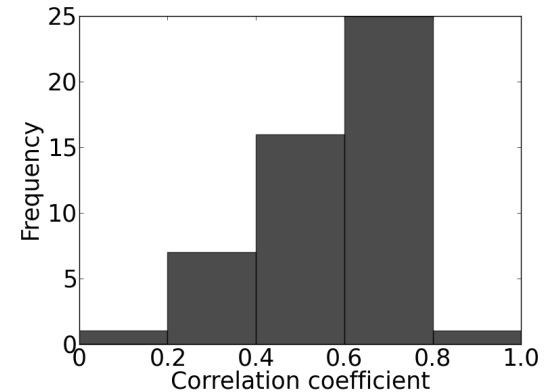

(c)

Figure 6. Histogram of bias, RMSE and correlation coefficient computed between soil moisture retrieved using CT and measured soil moisture. (a) Histogram of bias, (b) Histogram of RMSE, (c) Histogram of correlation.

A relatively poor performance of the $\mathrm{CT}$ model in few plots $(3,4,5,11,16,23,43,44)$ can be attributed to the fact that these plots often had extensive irrigation, sometimes resulting in ponding like condition. The ponding type condition decreases the roughness and hence decreases the $\mathrm{BC}$, which is opposite of the general trend, i.e., increase in soil moisture results in the increase in BC. Another possible 
reason might be the enhanced impact of difference in sensing depth between field and RADARSAT-2 measurements in irrigated areas [43]. Poor performance in the plot no. 19 could be attributed to the fact that it is situated in a foothill. Though correction for topography is performed, it can still be improved by a higher resolution DEM. Most of the plots having higher bias showed a significant correlation coefficient suggesting the effect of scaling the relative soil moisture into the absolute soil moisture using the soil information. This is consistent with the finding of [14], where scaling the $R S M$ into $S M$ with the help of soil information resulted in a bias dependent on soil type. The major source of error in the soil information could be due to the erroneous delineation of the soil classes and error coming from the pedo-transfer function. A better soil map could reduce this bias and hence provide a lower RMSE.

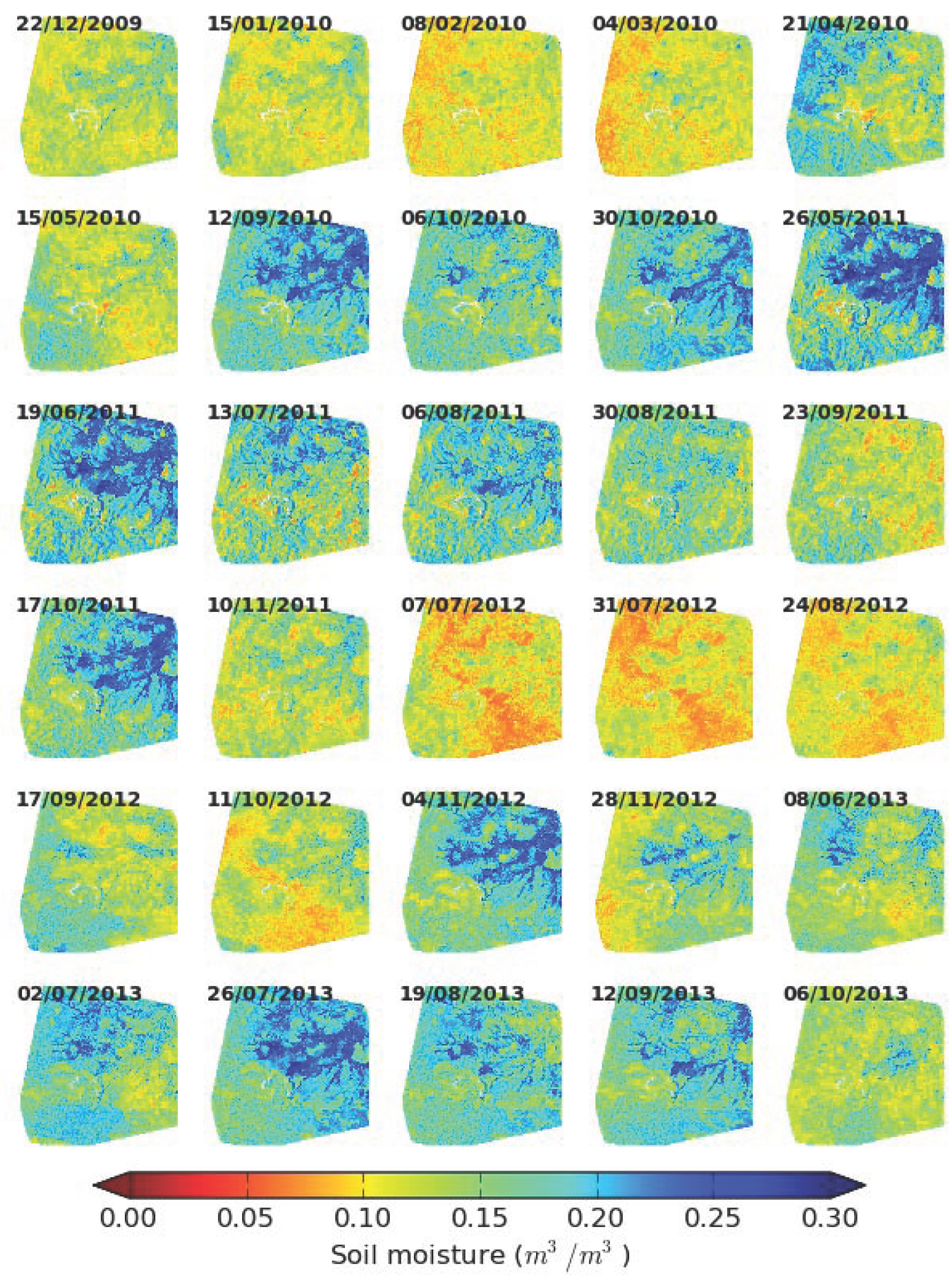

Figure 7. The soil moisture for the 30 RADARSAT-2 images. 
Spatial behavior of the retrieved soil moisture for all the 30 RADARSAT-2 images is shown in the Figure 7. The soil moisture shows a significant variability both in space and as well as in time, with the soil moisture ranging from 0.06 to $0.32\left(\mathrm{~m}^{3} / \mathrm{m}^{3}\right)$. Relatively higher soil moisture is observed in the valley of the watershed. Agricultural part of the study area shows a relatively higher variation in SM compared to the forested part, which is consistent with the observed temporal variation (maximum - minimum) of $7.4 \mathrm{~dB}$ and $5.4 \mathrm{~dB}$ in $\sigma_{H H}$ for the agricultural and forested part of the study area respectively. The relatively low variation observed in the SM in forested part could be due to the low vegetation penetration capability of $\mathrm{C}$ band. Temporal behavior of SM is also compared with the district average monthly precipitation provided by the Indian Meteorological Department (IMD) (http: //www.imd.gov.in/section/hydro/distrainfall/districtrain.html). Figure 8 shows the temporal variation of the mean retrieved SM using the CT model along with the monthly rainfall. For all the four years, the peak rainfall is observed around the month of September-November and minimum rainfall around December-February. The monthly rainfall showed a bi-modal behavior, showing a second peak around the month of March-May. The cumulative annual rainfall for the year 2010, 2011, 2012 and 2013 are $900.5 \mathrm{~mm}, 758.8 \mathrm{~mm}, 529.5 \mathrm{~mm}$, and $678.9 \mathrm{~mm}$ respectively. Year 2012 received lowest rainfall during the study period. The soil moisture showed a temporal behavior similar to the one shown by monthly rainfall with soil moisture for the December-March being relatively low. The soil moisture for the month of May-October was usually high except year 2012 which was a relatively dry year as shown by the monthly rainfall. A trend of decreasing soil moisture in the dry months (December 2009 to February 2010) is observed which is consistent with the fact that these months observed very low rainfall. Approximately, monthly rainfall lesser than $50 \mathrm{~mm}$ resulted in a decrease in soil moisture in time, and a monthly rainfall higher than $100 \mathrm{~m}$ showed the increasing trend. For the monthly rainfall between $50 \mathrm{~mm}$ and $100 \mathrm{~mm}$, the trend was found to be dependent on the initial condition of soil moisture.

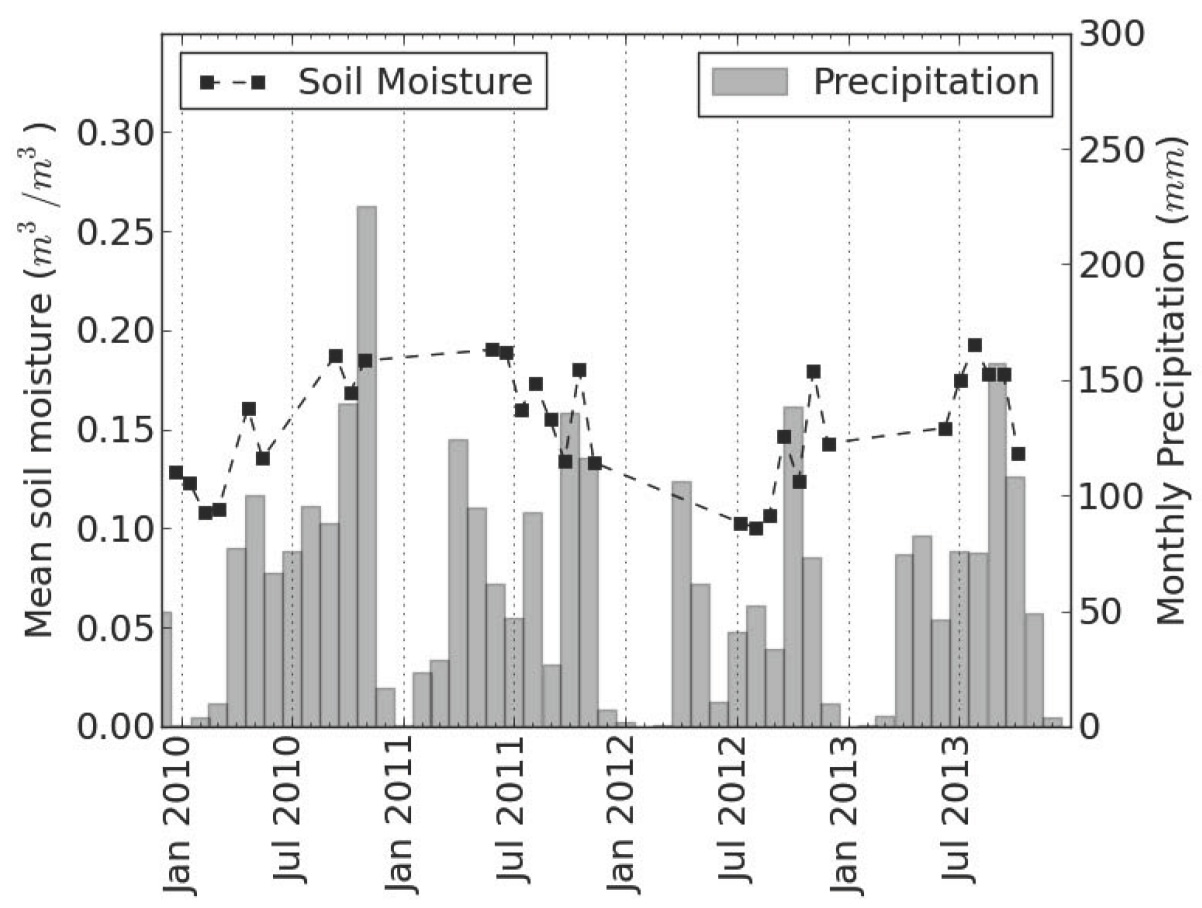

Figure 8. Temporal behaviour of mean (over space) soil moisture retrieved from RADARSAT-2. 


\subsection{Evaluation in terms of Data Availability}

All the three models considered in the current study rely on time series of images to retrieve soil moisture. It is thus desirable to know how the number of images available impact the retrieval accuracy. Soil moisture is retrieved with different window size ranging from 3 to 30 at an interval of 3 . Similar window size is used to retrieve soil moisture from all the three models considered and for all the four polarization. Figure 9 shows the RMSE for the three model considered and for all the four polarization. Delta Index (DI) model performed relatively poor for all the four polarizations. Change detection (CD) and CT model showed similar performance at higher window size (more than 12 images). CT model outperformed the CD method for smaller window size (less than 12), which could be due to the fact that for $\mathrm{CD}$ only two data points are used for normalization while for CT entire time series is used for normalization. It is thus highly recommended to use the CT approach for retrieving SM when less than 12 images are available. The images used for retrieving the SM should encompass the temporal variability (dry and wet conditions) present in the SM.
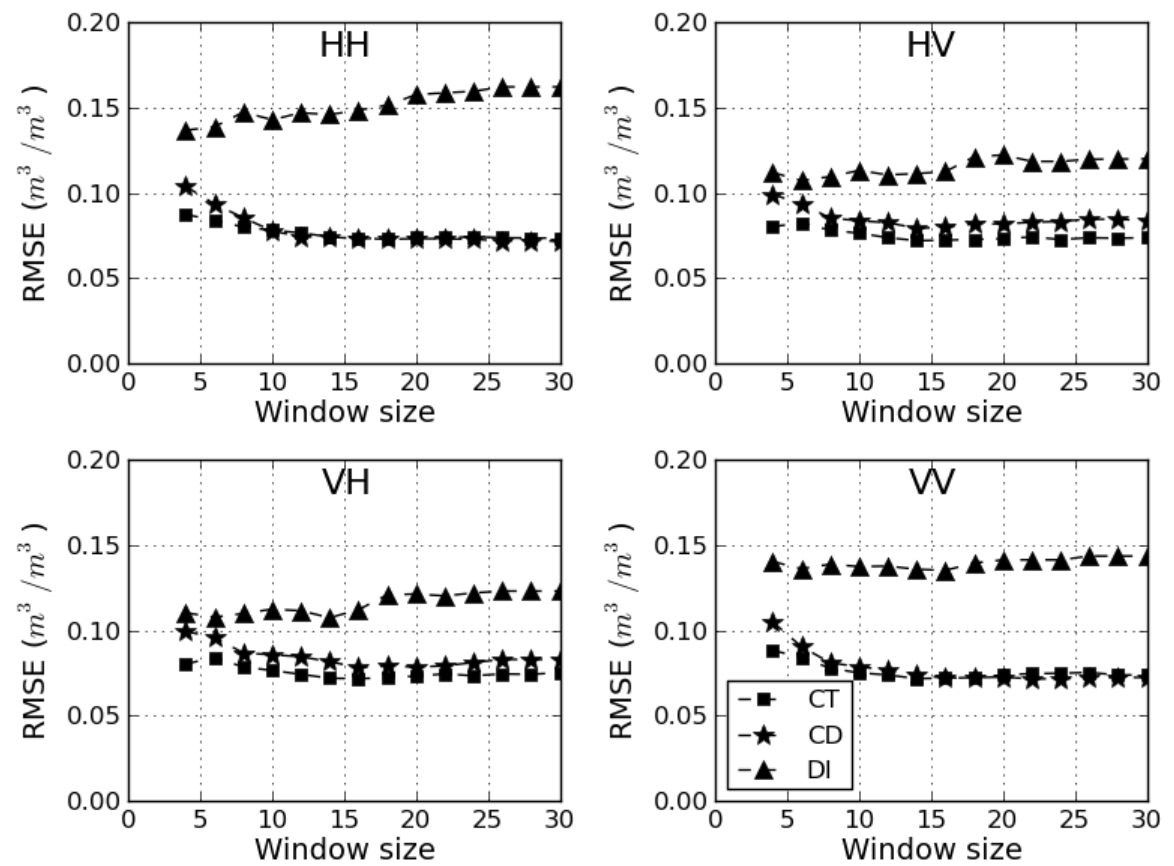

Figure 9. Effect of window size on soil moisture retrieval accuracy (CT-CDF transformation based model, CD—change detection, DI—delta index).

\subsection{Impact of Vegetation and Roughness}

The three models considered in the study assume negligible impact of the temporal variation in the vegetation and soil roughness. For C-band, at an incidence angle of around 15 degree this assumption is reasonable $[44,45]$. At an incidence angle higher than 15 degree, the temporal variation of soil roughness and vegetation might impact the $\mathrm{BC}$. The impact will be relatively higher for a relatively higher incidence angle. Studies using the change detection approach observed that the major source of SM retrieval error is the noise of the backscatter measurements and the impact of seasonal vegetation cover is about one order of magnitude smaller. 
Taconet et al. [46] suggested that for wheat canopy, at an incidence angle of 21 degree, $\mathrm{BC}$ requires a correction of $1 \mathrm{~dB}$ per $1 \mathrm{~kg} / \mathrm{m}^{2}$. The biomass for the agricultural plots in the study area are less than approximately $3 \mathrm{~kg} / \mathrm{m}^{2}$. A sensitivity analysis is performed to evaluate the impact of uncertainty in the $\mathrm{BC}$ on the soil moisture retrieval accuracy. The time series of $\mathrm{BC}$ is perturbed with random variable having normal distribution with zero mean and a given standard deviation. Same perturbed time series is used in retrieving the soil moisture from the three models. Figure 10 shows the RMSE in retrieving the soil moisture for different level of standard deviation (std.) of error in the BC for the three models and all the four polarization. DI model showed significant increase in the RMSE with the increase in the standard deviation of error, which could be due to the reason that it normalize the data with one data point and any error in that particular data point will introduce the error in entire time series of retrieved soil moisture. CD and CT showed the similar behavior showing a marginal increase (RMSE increased approximately from 0.07 to 0.10 for the increase in standard deviation of error from 0 to 3.5 respectively) in the RMSE with the increase in standard deviation of error.
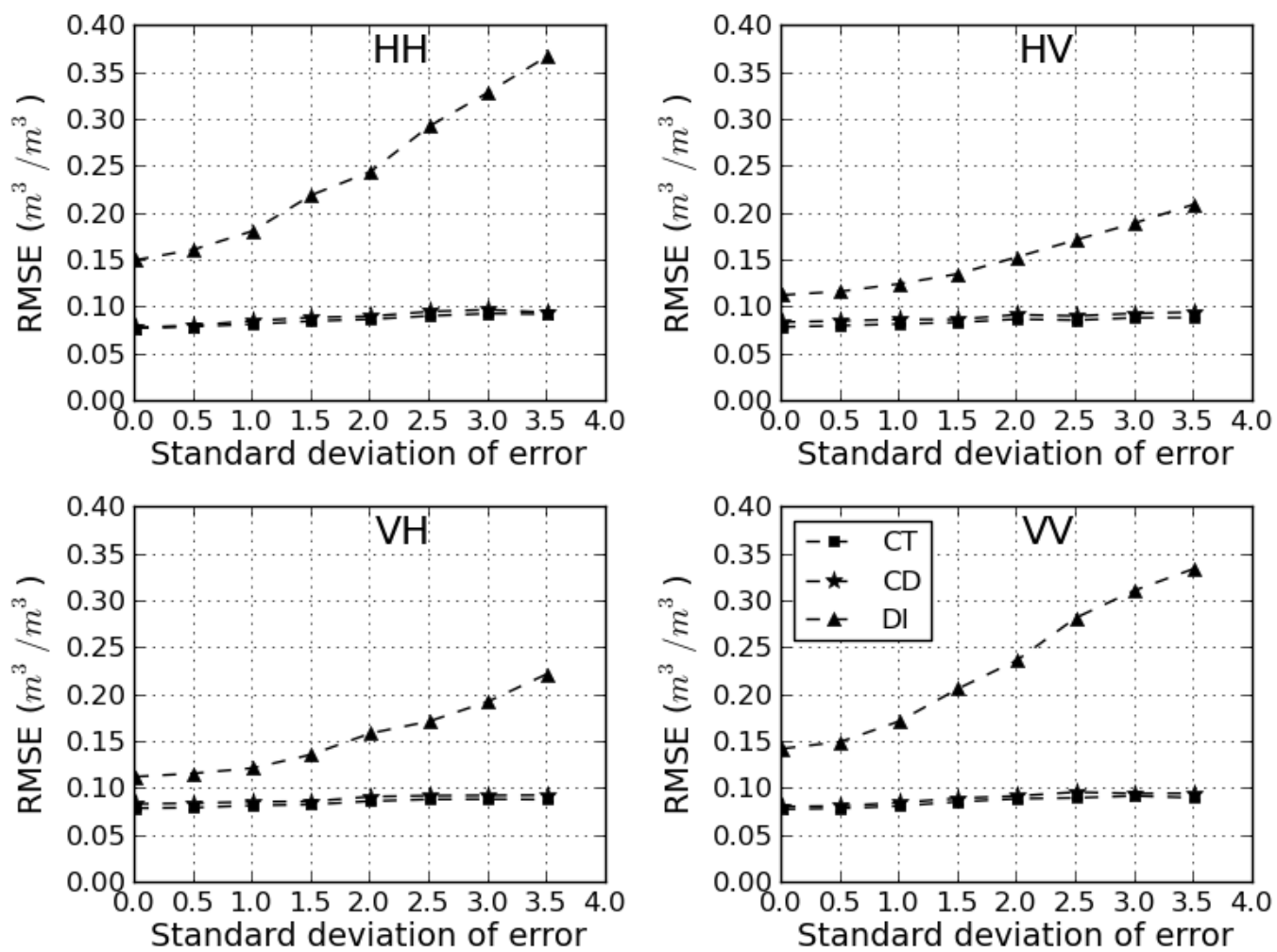

Figure 10. Effect of error in backscatter coefficient on the retrieval accuracy (CT-CDF transformation based model, CD—change detection, DI—delta index).

The retrieval of soil moisture can be improved by accounting for the contribution of vegetation in $\mathrm{BC}$ by using Water Cloud model [47]. Such a correction requires crop specific parameters, and a crop map at the watershed scale. Since, no crop map is available for the study area, and data only from the lower incidence angle is used which can penetrate the modest vegetation, no correction for vegetation is applied in the current work. Kim et al. [48] estimated the vegetation water content from Radar Vegetation Index (RVI) based on a linear regression model. The RVI is less impacted by environmental condition [49], and is defined as,

$$
R V I=\frac{8 \sigma_{H V}}{\sigma_{H H}+\sigma_{V V}+2 \sigma_{H V}},
$$


where, $\sigma$ is $\mathrm{BC}$ in linear unit and subscripts refer to the polarization. RVI can be used as a proxy to quantify the impact of higher and lower stages of vegetation. To quantify the effect of the different stages of vegetation, the RMSE for the retrieved soil moisture is computed for the lower and higher values of RVI. For each plot, RVI is classified into two groups by using the threshold of median. Then, RMSE are computed separately for these two group for all the 50 plots. Two tailed Welch's t-test is used to compare if the expected value of RMSE for lower and higher vegetation are statistically identical. The computed t-statistic for the test is 1.586 with $p$-value of 0.116 . It means that at $5 \%$ significance level the mean are identical. This could be explained by a relatively lower incidence angle of RADARSAT- 2 images used in the study. It can be concluded that the error introduced by not correcting for vegetation might be bringing relatively lower uncertainty compared to other sources (e.g., soil information).

RMSE for each image is computed by comparing the retrieved SM from HH polarization using the CT model. Temporal behavior of the computed RMSE along with the mean (averaged over 50 plots) RVI is presented in Figure 11. Mean RVI shows the seasonal cropping patters observed in the study area, with peak observed around September in all the four years. A moderate correlation of 0.45 is observed between the time series of RVI and RMSE. This could be probably due to the presence of different types of vegetation resulting in differences in scattering behavior, including other factors (soil roughness, soil parameters and soil wetness). However, a relatively higher value of RMSE is observed when there is a seasonal peak in the RVI. This suggests that the moderate relationship between the RVI and RMSE can not be used to quantify the retrieval error, however the RVI can be used to identify the images having the relatively higher vegetation biomass and mask them. Four images belonging to the seasonal peak value of mean RVI are masked which have RMSE of 0.094, 0.086, $0.079 \mathrm{~m}^{3} / \mathrm{m}^{3}$.

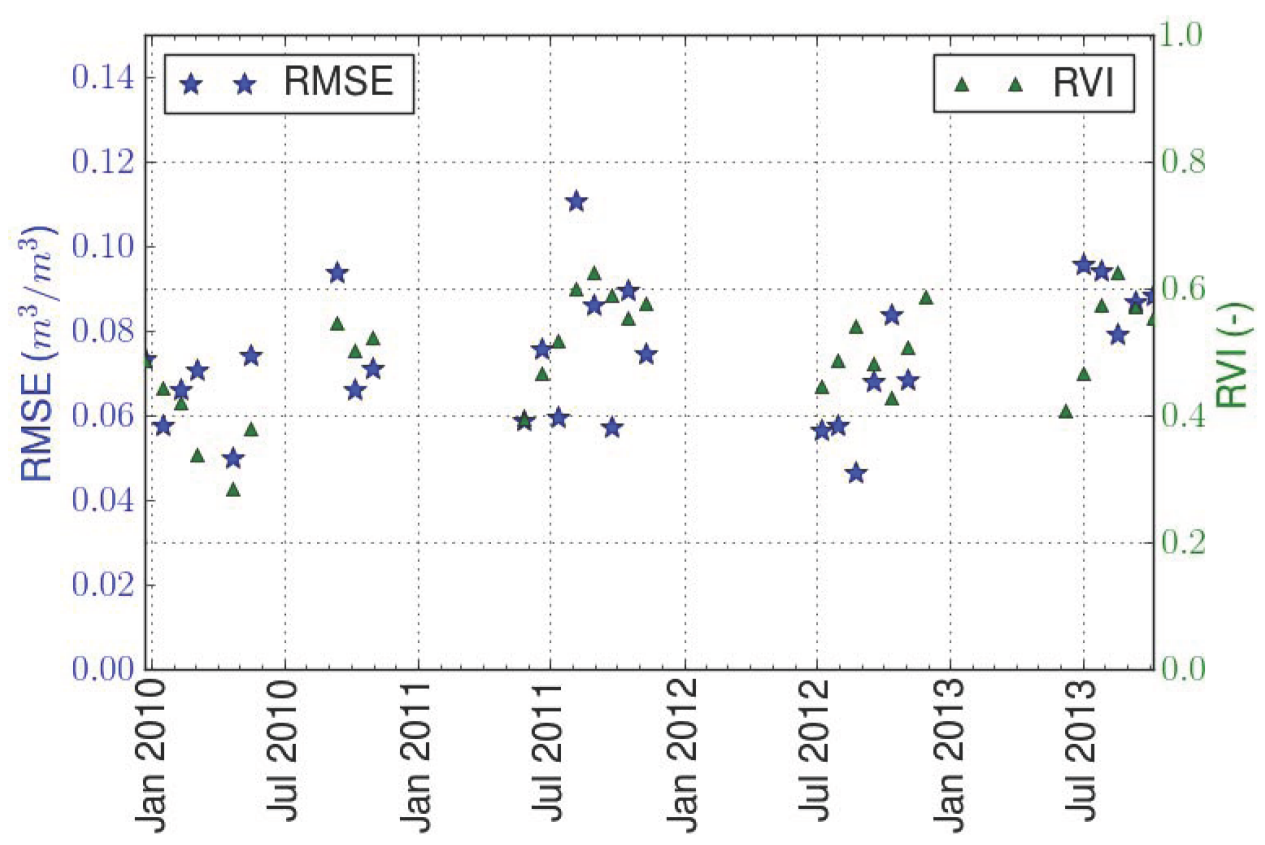

Figure 11. Temporal behaviour of mean RVI, and RMSE computed by comparing the retrieved SM from $\mathrm{HH}$ polarization by using the CT model for each image.

Using Integral Equation Model (IEM) [6], the behavior of $\sigma_{H H}$ is modeled in terms of incidence angle and soil roughness mean standard deviation height $\left(H_{r m s}\right)$ by assuming the exponential correlation function and a correlation length of $6 \mathrm{~cm}$ and SM equal to $0.20 \mathrm{~m}^{3} / \mathrm{m}^{3} . H_{r m s}$ is assumed to vary from 
0.6 to $1.2 \mathrm{~cm}$. Simulated behavior of $\sigma_{H H}$ is shown in Figure 12. It can be seen from the figure, the minimum variation in the $\sigma_{H H}$ due to the $H_{r m s}$ is observed at an incidence angle of about 17 degree, and higher or lower incidence angle than this results in a relatively higher variation of $\sigma_{H H}$. At an incidence angle of 23 degree, which is used in the current study, a saturation of $\sigma_{H H}$ is observed at higher value of $H_{r m s}$ than $1.0 \mathrm{~cm}$. A variation of $2.12 \mathrm{~dB}$ in $\sigma_{H H}$ is observed for $H_{r m s}$ varying from 0.6 to $1.2 \mathrm{~cm}$, and the variation reduces to $0.5 \mathrm{~dB}$ for the range from 0.8 to $1.2 \mathrm{~cm}$. It should be noted that though the absolute value of $\mathrm{BC}$ depends upon the SM, the difference in $\mathrm{BC}$ due to the $H_{r m s}$ is independent of SM [50]. A similar impact of variability in soil roughness was observed by using the IEM model [51]. From Figure 10, it can be inferred that an error of $1 \mathrm{~dB}$ standard deviation in $\mathrm{BC}$ results in increase in RMSE by $0.01 \mathrm{~m}^{3} / \mathrm{m}^{3}$ approximately. Often agricultural field experiences $H_{r m s}>0.6 \mathrm{~cm}$ [52-56], except soil with a higher (more than 50\%) slit content as reported in [50,57]. In the study area, all soil tillages correspond to medium or high roughness and therefore the impact of temporal variation in soil roughness can be neglected.

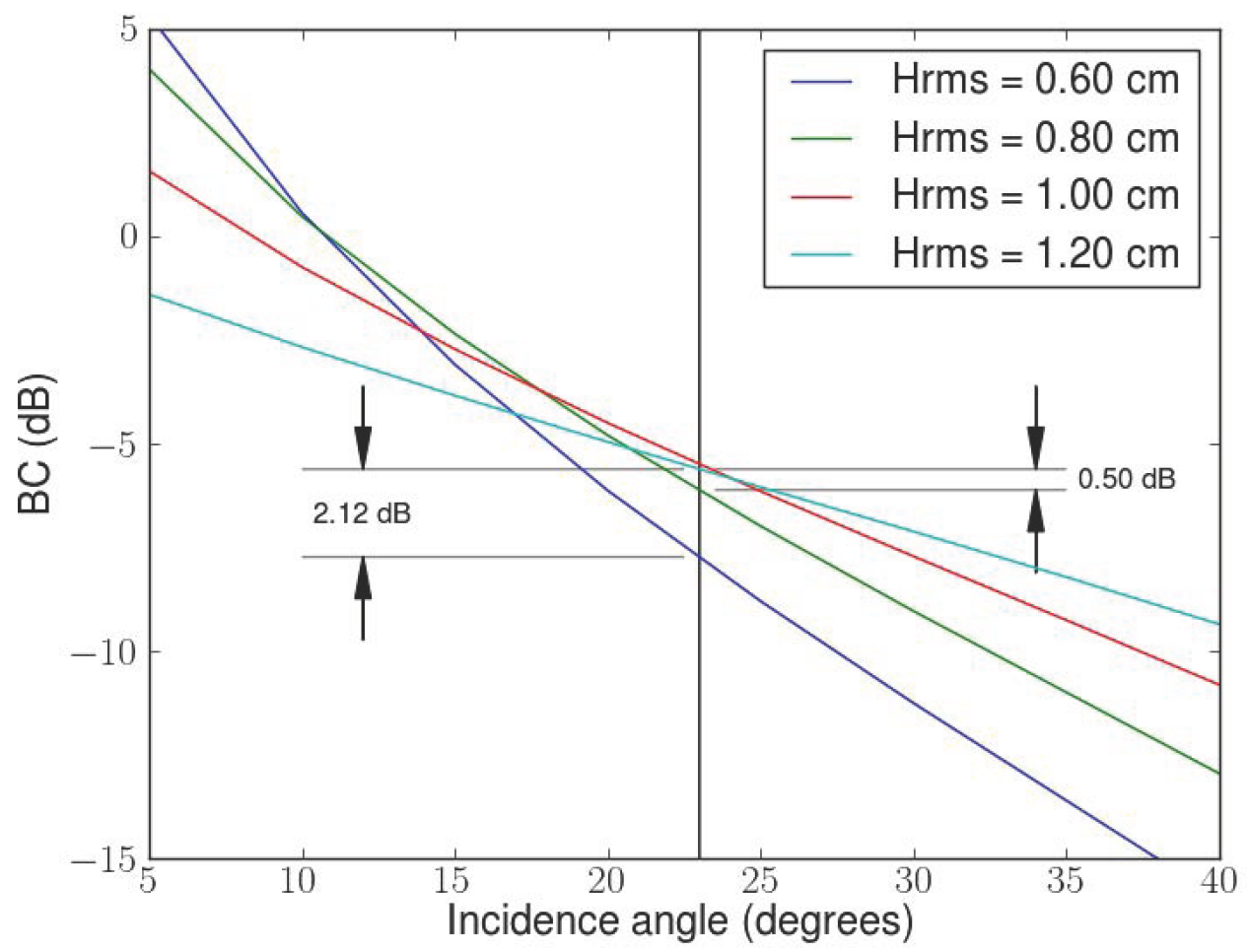

Figure 12. Variation in $\sigma_{H H}$ in terms of incidence angle and $H_{r m s}$.

To investigate the validity of assumption of maximum SM being equal to field capacity and minimum SM being equal to 0.5 of wilting point, frequency distribution of field measured SM is analyzed. It is observed that the field measured SM remains lower than the field capacity for $92 \%$ of the cases, and higher than the 0.5 of wilting point for $87 \%$ of the cases. A possible reason for SM falling outside the range of 0.5 of wilting point and field capacity could be the calibration error of $0.031 \mathrm{~m}^{3} / \mathrm{m}^{3}$ observed in the theta probe. For few field plots which were irrigated close to the satellite acquisition date, SM exceeded the field capacity and is observed to be closer to saturation value. The assumption that maximum soil moisture can be assumed to be equal to the field capacity might not hold true in the case of very dry or very wet region, and would need suitable change in the maximum soil moisture 
which can be calibrated as a function of field capacity for that region. Moran et al. [4] reported that the use of difference between dry and wet season $B C$ can normalize the effects of surface roughness and topography. In the current study, since a CDF approach is used, which normalize the $B C$ not only using the wet and dry season $B C$ but using the entire measured time series, the impact of surface roughness and topography can be reduced considering that the RADARSAT-2 images are at approximately same incidence angle. The CT approach has the advantage that it can work in the case of relationship between $S M$ and $B C$ being nonlinear and avoids the identification of dry and wet season images. The CT approach also explicitly account for the soil type, by normalizing using the field capacity and wilting point map. This is similar to the normalization performed by Dobson and Ulaby [58] using the field capacity only, the current approach being different in the sense that it uses wilting point also for the normalization. The normalization with the wilting point ensures the lower range of soil moisture into a physical range. Since current approach does not require any calibration parameter, it has the potential to be applied globally in the case of modest vegetation.

\subsection{Validation at SMOS Scale}

The soil moisture retrieved from RADARSAT-2 is up-scaled to the coarse scale to compare with the soil moisture from SMOS. The up-scaling is performed for the eight strategies mentioned in Table 2. The correlation coefficient and RMSE for the comparison are shown in Figure 13. To analyze the impact of SMOS pass direction (ascending/descending) the comparison is performed separately for only ascending pass data, for only descending pass data and for all the passes. The descending pass of SMOS showed a better comparison (a relatively higher correlation coefficient and a relatively lower RMSE) for all the eight strategies. Strategy number 3, 4, 7 and 8 outperformed the other strategies (a relatively higher correlation coefficient and a relatively lower RMSE) and the difference among these four best strategies $(3,4,7$ and 8$)$ is very minimal. The best strategies showed a RMSE of approximately $0.051 \mathrm{~m}^{3} / \mathrm{m}^{3}$ and a correlation coefficient of approximately 0.88 . The common factor among these four strategies is land cover, which means that the land cover is the significant factor while aggregating the soil moisture from the scale of RADARSAT- 2 to the scale of SMOS. This is consistent with the fact that SMOS level 2 did have the contribution from the forest area $[59,60]$. The under performance of ascending overpass is explained by the presence of radio frequency interferences. It is useful to note that this result can not be generalized for other regions.

The comparison of RADARSAT-2 retrieved SM with SMOS retrieved SM offers the opportunity to make a multi-scale (local to regional) validation with independent sources. However, the spatial resolution and representative depth is different. SM retrieved from RADARSAT-2 is upscaled based on the approach proposed by Al Bitar et al. [40] to bring it to the spatial resolution of SMOS. Representative depth of SM from RADARSAT-2 is typically representative of 0-2 cm [7] and from SMOS is typically representative of $0-5 \mathrm{~cm}$ [61]. Other studies associate more a $0-3 \mathrm{~cm}$ representative depth for soil moisture from L-band radiometers (SMOS, SMAP, Aquarius) [62,63]. The difference in representative depth might introduce the difference in estimated SM [64,65]. Nevertheless, the correlation between soil moisture at these depths is high [66]. To remove the impact of representative depth a bias correction using CDF matching is performed. In addition, at L-band and in passive mode (radiometer) the impact of 
vegetation is expected to be lower than C-band acquisitions [67]. Finally the comparison at SMOS scale offers the opportunity to make a multi-scale (local to regional) validation with independent sources.
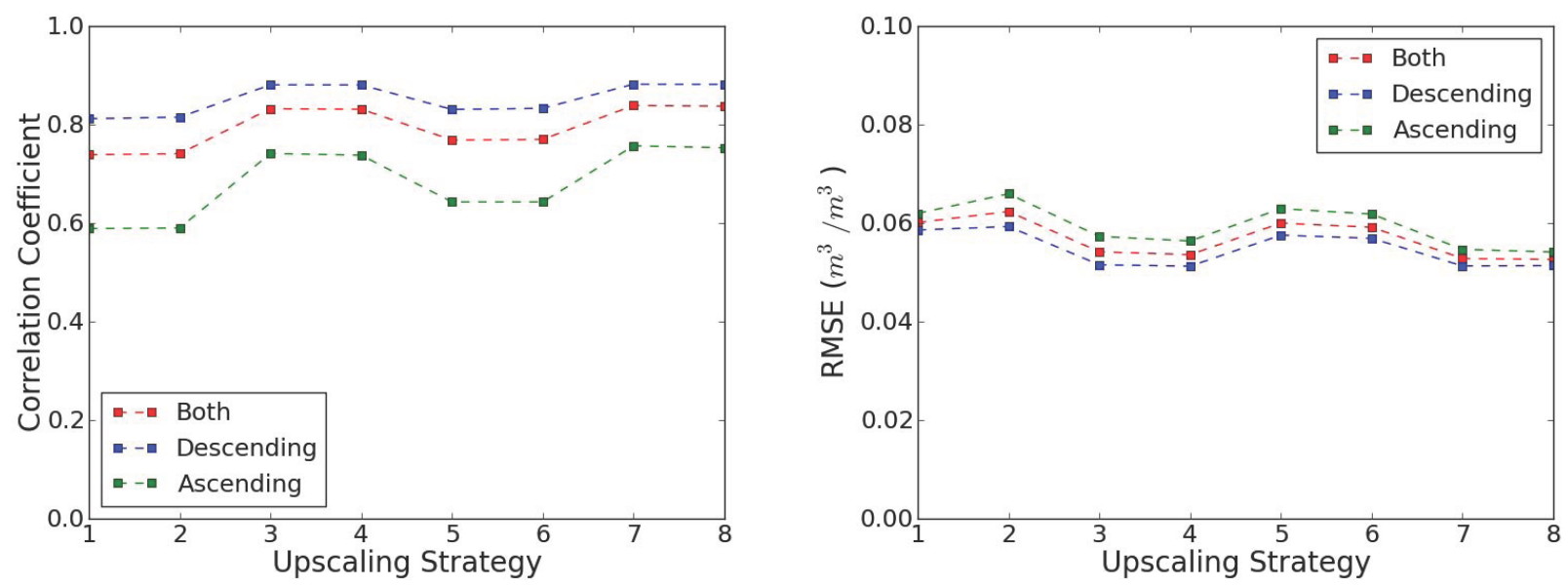

Figure 13. Comparison of the RADARSAT-2 soil moisture aggregated using eight strategies with the SMOS retrieved soil moisture in the ascending, descending and both the passes.

\section{Conclusions}

A methodology is developed to retrieve soil moisture from active microwave based on the CT approach. This approach requires a set of several backscatter images over time and soil (wilting point and field capacity) map but doest not require calibration of any parameter for a semi-arid region. The CT approach to retrieve soil moisture from active microwave is validated against the field data collected during 30 campaigns (concurrently with RADARSAT- 2 overpass) in 50 monitored field plots over a span of four years. The mean RMSE is around $0.04-0.06 \mathrm{~m}^{3} / \mathrm{m}^{3}$. Some of the plots showed a significant bias though having a good correlation due to the error in soil information. A better soil map could highly improve RMSE. The model is based on the assumption that minimum soil moisture is half of the wilting point and maximum soil moisture is equal to the field capacity in semi-arid region. This assumption might not hold true for very dry or very wet regions, and might require calibration of the minimum and maximum soil moisture in terms of the wilting point and field capacity. A relatively higher RMSE is observed when the vegetation is at peak, and such images can be masked using the RVI data or the crop cycle information. The impact of soil roughness variation can be ignored when $H_{r m s}$ is higher than $0.8 \mathrm{~cm}$ all the time.

The CT model is compared with the change detection and delta index models. CT model is found to be significantly better than delta index model. The performance of CT and CD is similar when sufficient data are available, but CT model outperformed the change detection model when relatively lesser number of data (less than 9 images) are available. This suggest the use of CT model for the region with sparse temporal data.

The impact of various source of spatial heterogeneities (soil texture, land cover and mean antenna foot print) is tested on the soil moisture aggregation from the scale of RADARSAT-2 to the scale of SMOS. It is found that there is significant impact of heterogeneity on the aggregation. Up-scaling with land-cover is impacting most with RMSE of approximately 0.05 and correlation coefficient of approximately 0.9 . 
This study highlights the importance of testing various spatial heterogeneities on the aggregation scheme. The impact of land cover on the aggregation can not be generalized for other regions as it depends on several factors. The quality of the coarse scale microwave data from SMOS depends on many effects like the presence of Radio frequency interference, the surface of water bodies in the area,the freezing of the soil, the presence of snow, the distance from the coast and the density of the vegetation cover $[40,68]$. Thus, even though the applied methodology for testing the impact of the heterogeneity is simple, it needs to be considered with care as it may prove inapplicable in certain conditions.

\section{Acknowledgments}

RADARSAT-2 data procured under RISAT-1 (Radar Imaging SATellite) utilization programme of ISRO is gratefully acknowledge. The authors acknowledges European Space Agency for the SMOSL2 dataset. The authors are also thankful for partial financial support received under the IISc-STC project (ISTC/CCE/MS/214). This work was also supported by the VIGISAT-CLS project which provided the Radarsat-2 satellite dataset from 2012 to 2014. The funding from CEFIPRA project 4700-W1 for salary of project personnel and field studies is acknowledged. Further funding from ISRO0198 for equipment and field measurements is also acknowledged. The authors would like to thank the help provided during field campaigns by the project staff Mr. P. Giriraj and by the farmers.

\section{Author Contributions}

S. K. Tomer and A. Al Bitar performed the modeling and analysis. S. Corgne and S. Bandyopadhyay helped in pre-processing and analysing the RADARSAT-2 data. K. Sreelash and A. K. Sharma helped in conducting field campaigns. M. Sekhar supervised the field campaigns, reviewed the modelling and data analysis. S. K. Tomer, A. Al Bitar and M. Sekhar prepared the first draft of the manuscript with help from other authors. M. Zribi performed the IEM modelling. M. Zribi and Y. Kerr provided feedback on the analysis and helped in writing the results and discussion section. All authors reviewed and provided feedback to the final manuscript.

\section{Conflicts of Interest}

The authors declare no conflict of interest.

\section{References}

1. Lakshmi, V. Remote sensing of soil moisture. ISRN Soil Sci. 2013, doi:10.1155/2013/424178.

2. Wood, E.F.; Roundy, J.K.; Troy, T.J.; van Beek, L.; Bierkens, M.F.; Blyth, E.; de Roo, A.; Döll, P.; Ek, M.; Famiglietti, J.; et al. Hyperresolution global land surface modeling: Meeting a grand challenge for monitoring Earth's terrestrial water. Water Resour. Res. 2011, doi:10.1029/2010WR010090.

3. Lakshmi, V. The role of satellite remote sensing in the prediction of ungauged basins. Hydrol. Process. 2004, 18, 1029-1034. 
4. Moran, M.S.; Peters-Lidard, C.D.; Watts, J.M.; McElroy, S. Estimating soil moisture at the watershed scale with satellite-based radar and land surface models. Can. J. Remote Sens. 2004, 30, 805-826.

5. Narayan, U.; Lakshmi, V.; Jackson, T.J. High-resolution change estimation of soil moisture using L-band radiometer and radar observations made during the SMEX02 experiments. IEEE Trans. Geosci. Remote Sens. 2006, 44, 1545-1554.

6. Fung, A.K.; Li, Z.; Chen, K.S. Backscattering from a randomly rough dielectric surface. IEEE Trans. Geosci. Remote Sens. 1992, 30, 356-369.

7. Zribi, M.; Gorrab, A.; Baghdadi, N.; Lili-Chabaane, Z.; Mougenot, B. Influence of radar frequency on the relationship between bare surface soil moisture vertical profile and radar backscatter. IEEE Geosci. Remote Sens. Lett. 2014, 11, 848-852.

8. Kelly, R.; Davie, T.; Atkinson, P. Explaining temporal and spatial variation in soil moisture in a bare field using SAR imagery. Int. J. Remote Sens. 2003, 24, 3059-3074.

9. Shoshany, M.; Svoray, T.; Curran, P.J.; Foody, G.M.; Perevolotsky, A. The relation between ERS-2 SAR backscatter and soil moisture: Generalization from a humid to semi-arid transect. Int. J. Remote Sens. 2000, 21, 2337-2343.

10. Sano, E.E.; Huete, A.R.; Troufleau, D.; Moran, M.S.; Vidal, A. Relation between ERS-1 synthetic aperture radar data and measurements of surface roughness and moisture content of rocky soils in a semiarid rangeland. Water Resour. Res. 1998, 34, 1491-1498.

11. Paloscia, S.; Pettinato, S.; Santi, E.; Notarnicola, C.; Pasolli, L.; Reppucci, A. Soil moisture mapping using Sentinel-1 images: Algorithm and preliminary validation. Remote Sens. Environ. 2013, 134, 234-248.

12. Pasolli, L.; Notarnicola, C.; Bertoldi, G.; Bruzzone, L.; Remelgado, R.; Greifeneder, F.; Niedrist, G.; Della Chiesa, S.; Tappeiner, U.; Zebisch, M. Estimation of soil moisture in mountain areas using SVR technique applied to multiscale active radar images at C-band. IEEE J. Sel. Top. Appl. Earth Obs. Remote Sens. 2015, 8, 262-283.

13. Moran, M.S.; McElroy, S.; Watts, J.M.; Peters-Lidar, C. Radar remote sensing for estimation of surface soil moisture at the watershed scale. In Proceedings of Modelling and Remote Sensing Applied in Agriculture (US and Mexico), Aquascalientes, Mexico, 2-6 June 2003; pp. 91-106.

14. Wagner, W.; Lemoine, G.; Rott, H. A method for estimating soil moisture from ERS scatterometer and soil data. Remote Sens. Environ. 1999, 70, 191-207.

15. Moran, S.; Hymer, D.; Qi, J.; Sano, E. Soil moisture evaluation using multi-temporal synthetic aperture radar (SAR) in semiarid rangeland. Agric. For. Meteorol. 2000, 105, 69-80.

16. Thoma, D.; Moran, M.; Bryant, R.; Rahman, M.; Holifield-Collins, C.; Skirvin, S.; Sano, E.; Slocum, K. Comparison of four models to determine surface soil moisture from C-band radar imagery in a sparsely vegetated semiarid landscape. Water Resour. Res. 2006, 42, doi:10.1029/2004WR003905.

17. Ulaby, F.T.; Moore, R.K.; Fung, A.K. Microwave Remote Sensing Active and Passive-Volume III: From Theory to Applications; Addison-Wesley: Boston, MA, USA, 1986.

18. Narvekar, P.S.; Entekhabi, D.; Kim, S.B.; Njoku, E.G. Soil moisture retrieval using L-band radar observations. IEEE Trans. Geosci. Remote Sens. 2015, 53, 3492 - 3506. 
19. Mladenova, I.E.; Jackson, T.J.; Bindlish, R.; Hensley, S. Incidence angle normalization of radar backscatter data. IEEE Trans. Geosci. Remote Sens. 2013, 51, 1791-1804.

20. Kottek, M.; Grieser, J.; Beck, C.; Rudolf, B.; Rubel, F. World map of the Köppen-Geiger climate classification updated. Meteorol. Z. 2006, 15, 259-263.

21. Barbiéro, L.; Parate, H.R.; Descloitres, M.; Bost, A.; Furian, S.; Mohan Kumar, M.; Kumar, C.; Braun, J.J. Using a structural approach to identify relationships between soil and erosion in a semi-humid forested area, South India. Catena 2007, 70, 313-329.

22. Sreelash, K.; Sekhar, M.; Ruiz, L.; Tomer, S.; Guérif, M.; Buis, S.; Durand, P.; Gascuel-Odoux, C. Parameter estimation of a two-horizon soil profile by combining crop canopy and surface soil moisture observations using GLUE. J. Hydrol. 2012, 456, 57-67.

23. Sreelash, K.; Sekhar, M.; Ruiz, L.; Buis, S.; Bandyopadhyay, S. Improved modeling of groundwater recharge in agricultural watersheds using a combination of crop model and remote sensing. J. Indian Inst. Sci. 2013, 93, 189-207.

24. Ahmed, N.; Mahtab, A.; Agrawal, R.; Jayaprasad, P.; Pathan, S.K.; Ajai; Singh, D.K.; Singh, A.K. Extraction and validation of Cartosat-1 DEM. J. Indian Soc. Remote Sens. 2007, 35, 121-127.

25. Karnataka State Remote Sensing Application Centre. Report on State Natural Resources Information System; Technical Report; 2007; unpublished.

26. Kerr, Y.H.; Waldteufel, P.; Richaume, P.; Wigneron, J.P.; Ferrazzoli, P.; Mahmoodi, A.; Al Bitar, A.; Cabot, F.; Gruhier, C.; Juglea, S.E.; et al. The SMOS soil moisture retrieval algorithm. IEEE Trans. Geosci. Remote Sens. 2012, 50, 1384-1403.

27. Schaap, M.G.; Leij, F.J.; van Genuchten, M.T. rosetta: A computer program for estimating soil hydraulic parameters with hierarchical pedotransfer functions. J. Hydrol. 2001, 251, 163-176.

28. Ulaby, F.T.; Moore, R.K.; Fung, A.K. Microwave Remote Sensing Active and Passive-Volume II: Radar Remote Sensing and Surface Scattering and Enission Theory; Addison-Wesley: Boston, MA, USA, 1982.

29. Lievens, H.; Verhoest, N.E.; Keyser, E.D.; Vernieuwe, H.; Matgen, P.; Álvarez-Mozos, J.; Baets, B.D. Effective roughness modelling as a tool for soil moisture retrieval from C-and L-band SAR. Hydrol. Earth Syst. Sci. 2011, 15, 151-162.

30. Kumar, S.; Kumar, P.; Gupta, M.; Nagawat, A. Performance comparison of median and wiener filter in image de-noising. Int. J. Comput. Appl. 2010, 12, 24-28.

31. Engdahl, M.; Minchella, A.; Marinkovic, P.; Veci, L.; Lu, J. Nest: An esa open source toolbox for scientific exploitation of sar data. In Proceedings of 2012 IEEE International Geoscience and Remote Sensing Symposium (IGARSS), Munich, Germany, 2012; pp. 5322-5324.

32. Wang, C.; Qi, J. Biophysical estimation in tropical forests using JERS-1 SAR and VNIR imagery. II. Aboveground woody biomass. Int. J. Remote Sens. 2008, 29, 6827-6849.

33. Narvekar, P.S.; Entekhabhi, D.; Kim, S.; Njoku, E. A robust algorithm for soil moisture retrieval from the Soil Moisture Active Passive mission RADAR observation. In Proceedings of 2013 IEEE International Geoscience and Remote Sensing Symposium (IGARSS), Melbourne, VIC, Australia, 21-26 July 2013; pp. 45-48.

34. Dubois, P.C.; Zyl, J.V.; Engman, E.T. Measuring soil moisture with imaging radars. IEEE Trans. Geosci. Remote Sens. 1995, 33, 916-926. 
35. Zribi, M.; Saux-Picart, S.; André, C.; Descroix, L.; Ottle, C.; Kallel, A. Soil moisture mapping based on ASAR/ENVISAT radar data over a Sahelian region. Int. J. Remote Sens. 2007, 28, 3547-3565.

36. Papaefthymiou, G.; Kurowicka, D. Using copulas for modeling stochastic dependence in power system uncertainty analysis. IEEE Trans. Power Syst. 2009, 24, 40-49.

37. Eilers, V.; Carter, R.; Rushton, K. A single layer soil water balance model for estimating deep drainage (potential recharge): An application to cropped land in semi-arid North-East Nigeria. Geoderma 2007, 140, 119 - 131.

38. Silverman, B.W. Density Estimation for Statistics and Data Analysis; CRC Press: Boca Raton, FL, USA, 1986.

39. Liu, Y.; Parinussa, R.; Dorigo, W.; De Jeu, R.; Wagner, W.; van Dijk, A.; McCabe, M.; Evans, J. Developing an improved soil moisture dataset by blending passive and active microwave satellite-based retrievals. Hydrol. Earth Syst. Sci. 2011, 15, 425-436.

40. Al Bitar, A.; Leroux, D.; Kerr, Y.H.; Merlin, O.; Richaume, P.; Sahoo, A.; Wood, E.F. Evaluation of SMOS soil moisture products over continental US using the SCAN/SNOTEL network. IEEE Trans. Geosci. Remote Sens. 2012, 50, 1572-1586.

41. Mladenova, I.; Lakshmi, V.; Walker, J.P.; Panciera, R.; Wagner, W.; Doubkova, M. Validation of the ASAR global monitoring mode soil moisture product using the NAFE'05 data set. IEEE Trans. Geosci. Remote Sens. 2010, 48, 2498-2508.

42. Pathe, C.; Wagner, W.; Sabel, D.; Doubkova, M.; Basara, J. Using ENVISAT ASAR global mode data for surface soil moisture retrieval over Oklahoma, USA. IEEE Trans. Geosci. Remote Sens. 2009, 47, 468-480.

43. Merlin, O.; Walker, J.P.; Panciera, R.; Escorihuela, M.J.; Jackson, T.J. Assessing the SMOS soil moisture retrieval parameters with high-resolution NAFE'06 data. IEEE Geosci. Remote Sens. Lett. 2009, 6, 635-639.

44. Ulaby, F.T.; Batlivala, P.P.; Dobson, M.C. Microwave backscatter dependence on surface roughness, soil moisture and soil texture: Part I - bare soil. IEEE Trans. Geosci. Electron. 1978, GE-16, 286-295.

45. Bernard, R.; Martin, P.; Thony, J.L.; Vauclin, M.; Vidal-Madjar, D. C-band radar for determining surface soil moisture. Remote Sens. Environ. 1982, 12, 189-200.

46. Taconet, O.; Vidal-Madjar, D.; Emblanch, C.; Normand, M. Taking into account vegetation effects to estimate soil moisture from C-band radar measurements. Remote Sens. Environ. 1996, $56,52-56$.

47. Sat Kumar.; Sekhar, M.; Bandyopadhyay, S. Assimilation of remote sensing and hydrological data using adaptive filtering techniques for watershed modeling. Curr. Sci. 2009, 97, 1196-1202.

48. Kim, Y.; Jackson, T.; Bindlish, R.; Lee, H.; Hong, S. Radar vegetation index for estimating the vegetation water content of rice and soybean. IEEE Geosci. Remote Sens. Lett. 2012, 9, 564-568.

49. Kim, Y.; van Zyl, J. A time-series approach to estimate soil moisture using polarimetric radar data. IEEE Trans. Geosci. Remote Sens. 2009, 47, 2519-2527.

50. Zribi, M.; Dechambre, M. A new empirical model to retrieve soil moisture and roughness from C-band radar data. Remote Sens. Environ. 2003, 84, 42-52. 
51. Álvarez-Mozos, J.; Verhoest, N.; Larrañaga, A.; Casalí, J.; González-Audícana, M. Influence of surface roughness spatial variability and temporal dynamics on the retrieval of soil moisture from SAR observations. Sensors 2009, 9, 463-489.

52. Jackson, T.; McNairn, H.; Weltz, M.; Brisco, B.; Brown, R. First order surface roughness correction of active microwave observations for estimating soil moisture. IEEE Trans. Geosci. Remote Sens. 1997, 35, 1065-1069.

53. Turner, R.; Panciera, R.; Tanase, M.A.; Lowell, K.; Hacker, J.M.; Walker, J.P. Estimation of soil surface roughness of agricultural soils using airborne LiDAR. Remote Sens. Environ. 2014, 140, 107-117.

54. Gherboudj, I.; Magagi, R.; Berg, A.; Toth, B. Soil moisture retrieval over agricultural fields from multi-polarized and multi-angular RADARSAT-2 SAR data. Remote Sens. Environ. 2011, 115, 33-43.

55. Zribi, M.; Chahbi, A.; Shabou, M.; Lili-Chabaane, Z.; Duchemin, B.; Baghdadi, N.; Amri, R.; Chehbouni, A. Soil surface moisture estimation over a semi-arid region using ENVISAT ASAR radar data for soil evaporation evaluation. Hydrol. Earth Syst. Sci. Discuss. 2011, 15, 345-358.

56. Le Morvan, A.; Zribi, M.; Baghdadi, N.; Chanzy, A. Soil moisture profile effect on radar signal measurement. Sensors 2008, 8, 256-270.

57. Álvarez-Mozos, J.; Casalí, J.; González-Audícana, M.; Verhoest, N.E. Assessment of the operational applicability of RADARSAT-1 data for surface soil moisture estimation. IEEE Trans. Geosci. Remote Sens. 2006, 44, 913-924.

58. Dobson, M.C.; Ulaby, F.T. Active microwave soil moisture research. IEEE Trans. Geosci. Remote Sens. 1986, GE-24, 23-36.

59. Lawrence, H.; Wigneron, J.P.; Richaume, P.; Novello, N.; Grant, J.; Mialon, A.; Al Bitar, A.; Merlin, O.; Guyon, D.; Leroux, D.; et al. Comparison between SMOS Vegetation Optical Depth products and MODIS vegetation indices over crop zones of the USA. Remote Sens. Environ. 2014, 140, 396-406.

60. Rahmoune, R.; Ferrazzoli, P.; Singh, Y.; Kerr, Y.; Richaume, P.; Al Bitar, A. SMOS retrieval results over forests: Comparisons with independent measurements. IEEE J. Sel. Top. Appl. Earth Obs. Remote Sens. 2014, 7, 3858-3866.

61. Kerr, Y.H.; Waldteufel, P.; Wigneron, J.P.; Martinuzzi, J.; Font, J.; Berger, M. Soil moisture retrieval from space: The Soil Moisture and Ocean Salinity (SMOS) mission. IEEE Trans. Geosci. Remote Sens. 2001, 39, 1729-1735.

62. Raju, S.; Chanzy, A.; Wigneron, J.P.; Calvet, J.C.; Kerr, Y.; Laguerre, L. Soil moisture and temperature profile effects on microwave emission at low frequencies. Remote Sens. Environ. 1995, 54, 85-97.

63. Escorihuela, M.J.; Chanzy, A.; Wigneron, J.P.; Kerr, Y. Effective soil moisture sampling depth of L-band radiometry: A case study. Remote Sens. Environ. 2010, 114, 995-1001.

64. McCabe, M.; Gao, H.; Wood, E. Evaluation of AMSR-E-derived soil moisture retrievals using ground-based and PSR airborne data during SMEX02. J. Hydrometeorol. 2005, 6, 864-877. 
65. Mladenova, I.; Lakshmi, V.; Jackson, T.J.; Walker, J.P.; Merlin, O.; de Jeu, R.A.M. Validation of AMSR-E soil moisture using L-band airborne radiometer data from National Airborne Field Experiment 2006. Remote Sens. Environ. 2011, 115, 2096-2103.

66. Qiu, J.; Crow, W.T.; Nearing, G.S.; Mo, X.; Liu, S. The impact of vertical measurement depth on the information content of soil moisture times series data. Geophys. Res. Lett. 2014, 41, 4997-5004.

67. Bizzarri, B.; Wigneron, J.P.; Kerr, Y. Operational readiness of microwave remote sensing of soil moisture for hydrologic applications. Nord. Hydrol. 2007, 38, 1-20.

68. Al-Yaari, A.; Wigneron, J.P.; Ducharne, A.; Kerr, Y.; de Rosnay, P.; de Jeu, R.; Govind, A.; Al Bitar, A.; Albergel, C.; Muñoz-Sabater, J.; et al. Global-scale evaluation of two satellite-based passive microwave soil moisture datasets (SMOS and AMSR-E) with respect to Land Data Assimilation System estimates. Remote Sens. Environ. 2014, 149, 181-195.

(c) 2015 by the authors; licensee MDPI, Basel, Switzerland. This article is an open access article distributed under the terms and conditions of the Creative Commons Attribution license (http://creativecommons.org/licenses/by/4.0/). 